$$
\begin{aligned}
& \text { برنامج إلكتروني لتنمية بعض المهارات التكنولوجية للطالبة المعلمة برياض الأطفال عبر الويب } \\
& \text { سماح عبد الفتاح مرزوق } \\
& \text { جامعة القاهرة، مصر }
\end{aligned}
$$

قُبل بتاريخ:

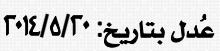

استُلم بتاريخ:

هدفت الدراسة إلى التعرف على دور التدريب الإلكتروني من خلال برنامج إلكتروني تدرييي؛ لتتمية بعض المهارات التكنولوجية للطالبة المعلمة على استخدام التكنولوجيا يوٌ التعليم عبر الويب، وتكونت عينة البحث من مجموعة من طالبات الفرقة الثالثة بكلية رياض الأطفال

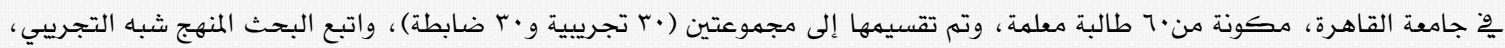

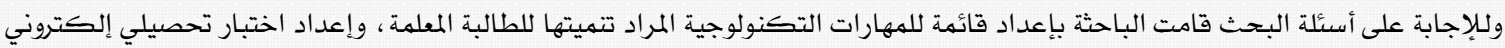

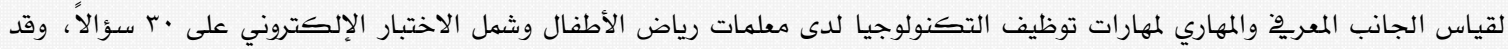

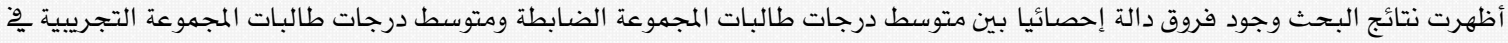

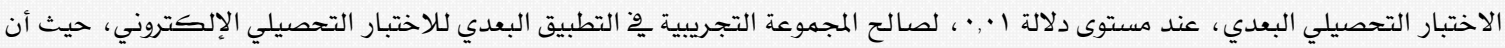

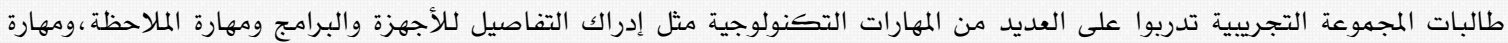

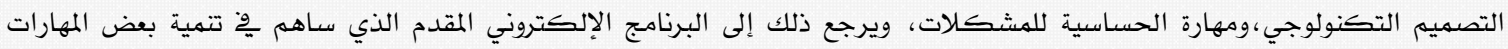
التكنولوجية للطالبة المعلمة.

$$
\text { كلمات مفتاحية : البرنامج الإلكتروني، المهارات التكنولوجية ، الطالبة المعلمة برياض الأطفال، الويب. }
$$

\title{
An Electronic Program for D eveloping Some of the Technological Skills of the Kindergarten Student Teachers Via the Web
}

Samah A. Marzouk*

Cairo University, Eygpt

The purpose of this study was to explore the role of an electronic training program on developing some technological skills of the student teacher to use technology in learning via web. The participants were 60 third-year students at the Faculty of Kindergarten, Cairo University. The quasi-experimental design was used. To answer the questions of the study, the researcher developed a list of technological skills that are essential for the student teacher and an electronic achievement test to assess the cognitive and technical skills of using technology for kindergarten teachers. The results of the study showed significant differences between the control group and the experimental group in the achievement test in favor of the experimental group ( $p=$ 0.01). The experimental-group students achieved gains as they received training on technological skills such as perceiving details of machines and programs, the observation skill, the technological design technology, and the sensitivity to problems skill due to the electronic program offered in the current study.

Keyw ords: Electronic program, technological skills, kindergarten student teacher, web.

*samah_marzok@yahoo.com 
وأصبح وسيلة فعالة لتحسين نوعية النعليم توفير جودة عالية

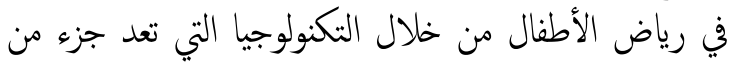

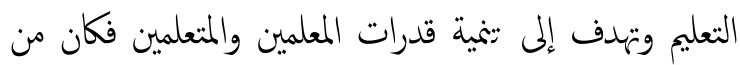

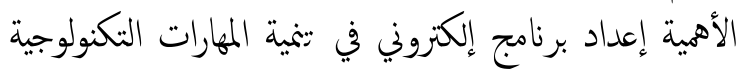

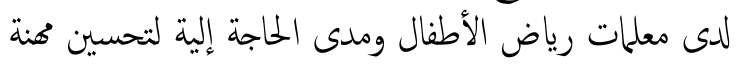

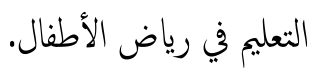

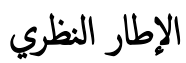

المحور الأول: التدريب الإكترونى عبر الويب: يعّد التدريب

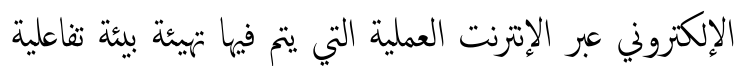
غنية بالتطبيقات المعتمدة على تقنية الحاسب الآلي وشبكاته

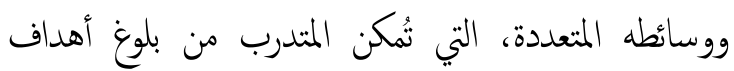

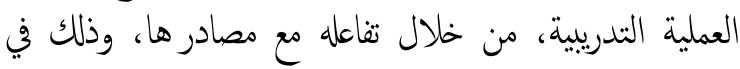

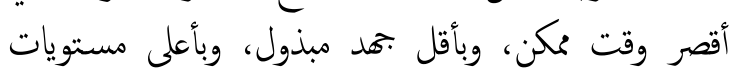

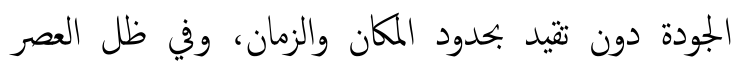
الراهن الذي نعيشه فإنه من الضروري تدريب الطالبة المعلمة

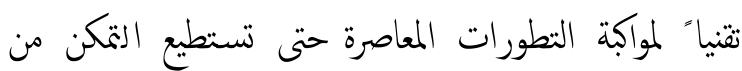

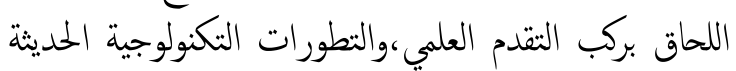

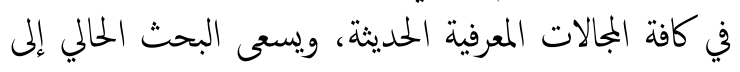

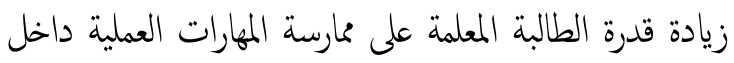

$$
\text { قاعات الروضة بكفاءة عالية. }
$$

ومن الدراسات التي أكدت على أهمية استخدام شبكة

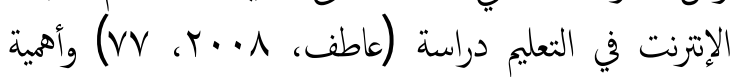
نشر ثنافة التعليم والتدريب في المجتع، والتي تمكن من تحسين

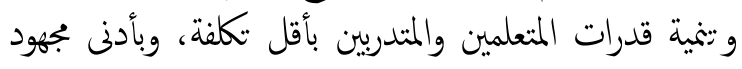

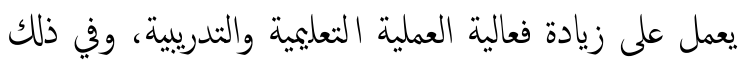

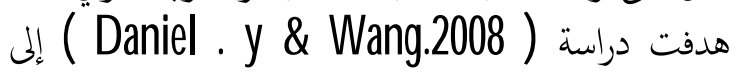
تطبيق التعليم الإكنتروني القائم على الويب كطريقة من طرق

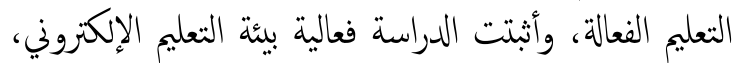

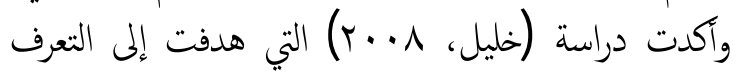

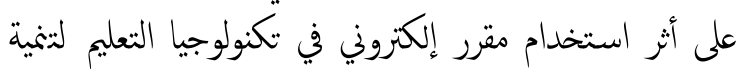

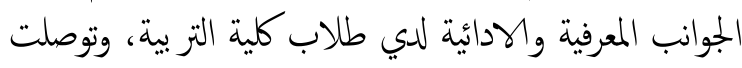
نتائج الدراسة إلى فعالية الموقع التعليمي في تنمية التمانية التحصيل

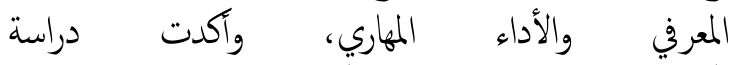
(Coffman, Teresa, 2004)

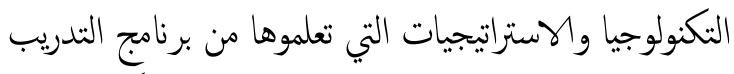

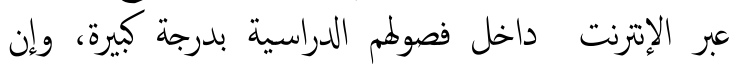

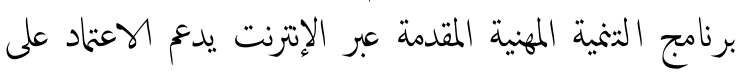

يمتاز العصر الحالي بالتقدم الهائل في مجالات تكنولوجيا النعليم

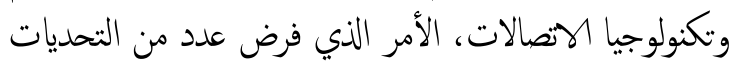

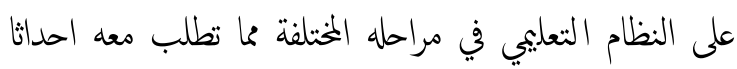

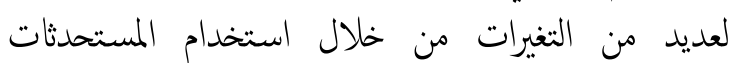

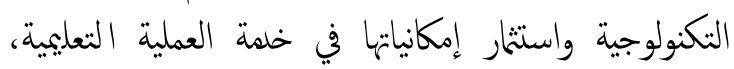

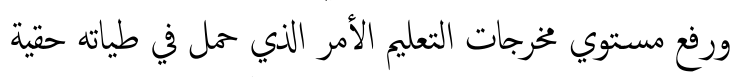

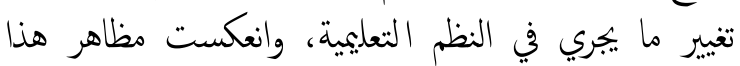

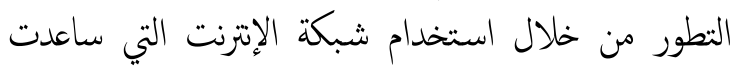

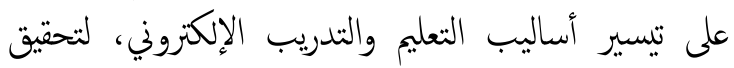

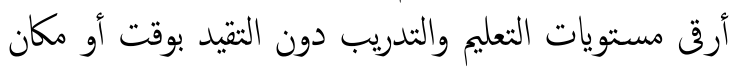

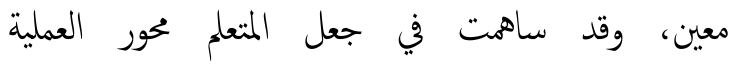
التربوية،ووفرت له المواقف التعليمية التي تسمح له بلنياء معارفه وتنمية حماراته وقدراته وتفكيره وتشكيل اتجاهاته من خلال

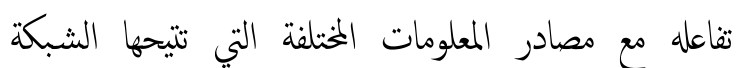

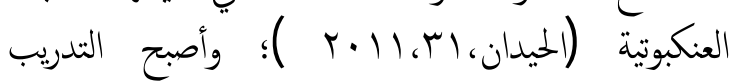

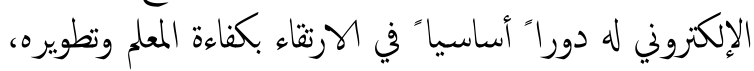

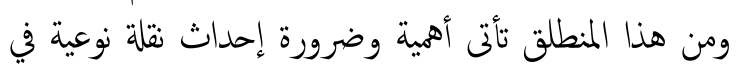

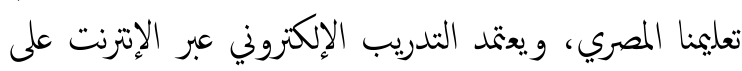

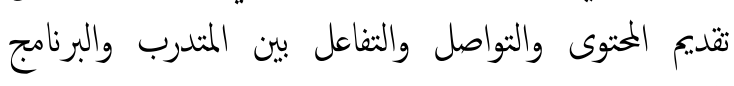
التدريبي. وهناك العديد من الدراسات العربية والأجنية التي تناولت

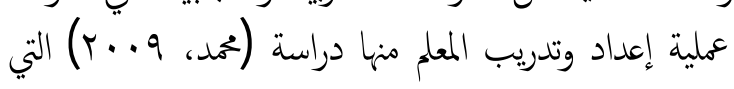

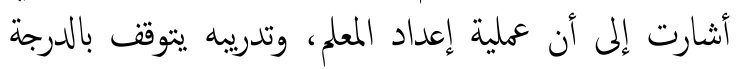

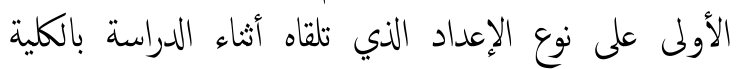

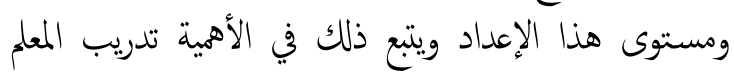

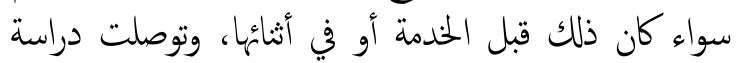

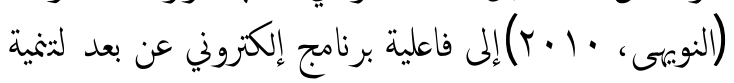

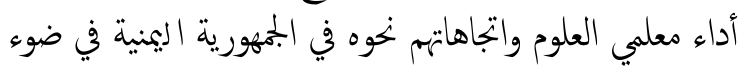

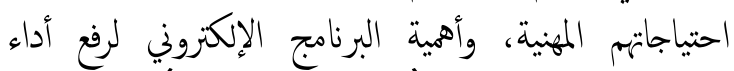

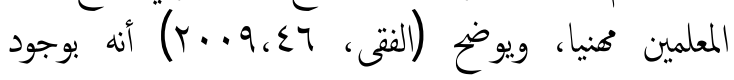
التدريب الإلكنروني المعتمد على الانترنت، أصبح هناك إمكانية

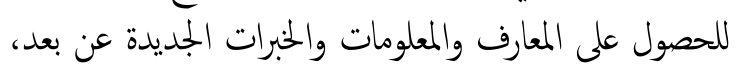

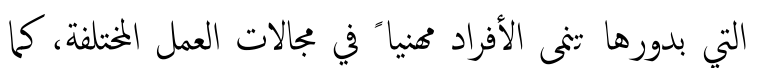

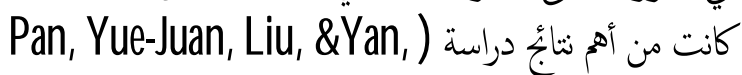
2010)، ودراسة (Fung Chanel, Kit-Ho, 2008) ودراسة (Hampton, Virginia Ruth, 2000)، توصلت هذه الدراسات إلى فعالية نظام الجودة في رياض الأطفال، 
الرسوم الثابتة والصور الثابتة، الرسوم المتحركة

$$
\text { والصور المتحركة. }
$$

ع. التصميم التعلييي والأساليب التكنولوجية المستخدمة:

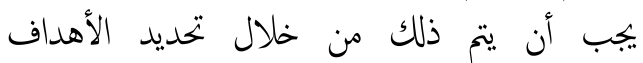

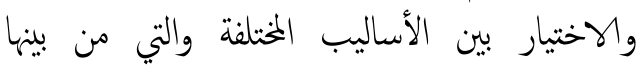
الاتصال بالإنترنت ونظم التشغيل والفيديو الفعال. 0. النغذية الراجعة، يجب الإمداد بها لتحسين الأداء وتوظيف المعرفة وتطبيقها وفقاء للقدرات.

إن استخدام كافة المستحدثات التكنولوجية في العملية

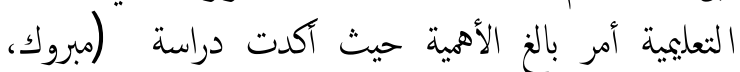

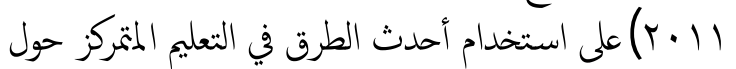

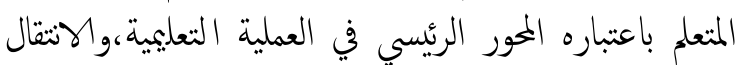

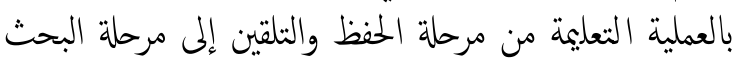
والتفكير، وحل المشكلات، وهذه الأسس التي تقوم عليها

$$
\text { آليات التعلم في القرن الحادي والعشرين. }
$$

وأثارت العديد من الدراسات بأهية استخدام المواقع التعليمية في تنمية محارات ومفاهيم واتجاهات المعلمين والمتعلمين، ومنها دراسة (Robert A, Sheidet, 2003)، والتي أكدت في نتائجها على وجود اتجاه ايجابي نحو زيادة نسبة المتعلمين الذين

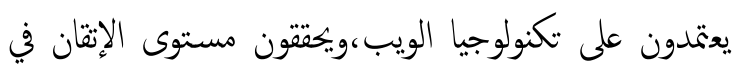

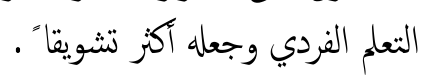

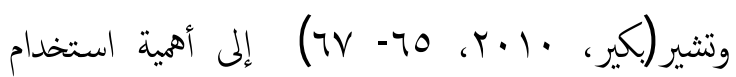

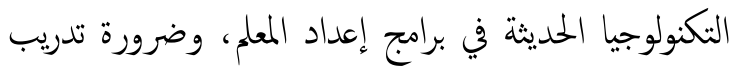

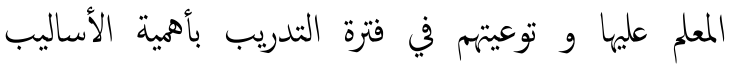

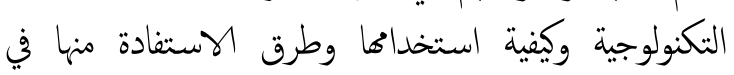
التعليم النورج

ثانيا ' مراحل تصميم التدريب الإلكروني' نموذج التصميم

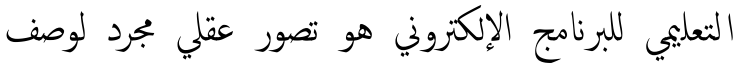

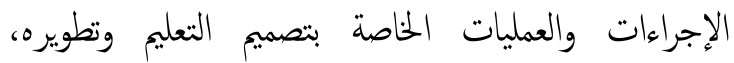

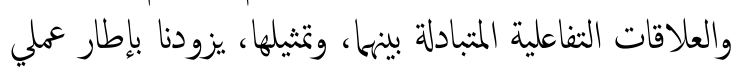

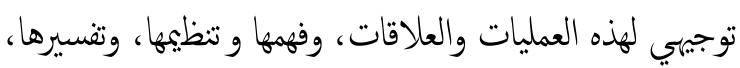

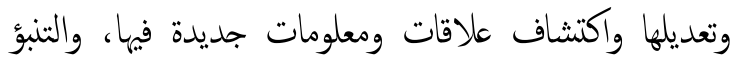

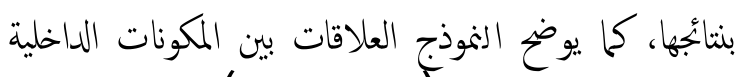

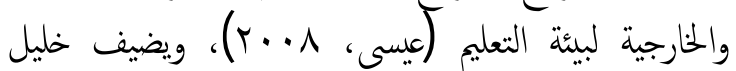

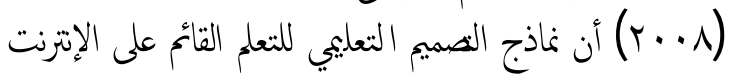

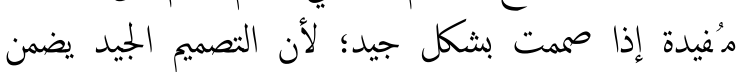

مداخل التعلم المتركزة حول المتعلم والتي تشجع الإكتشاف الذاتي، والمشاركة الفعالة، والتعاون بين الأقران والخبراء.

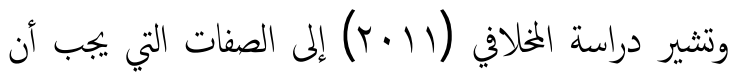

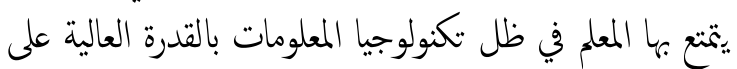

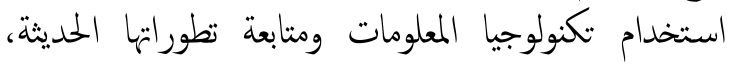

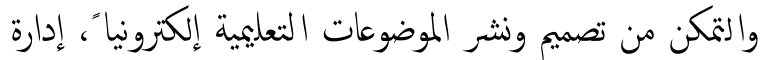

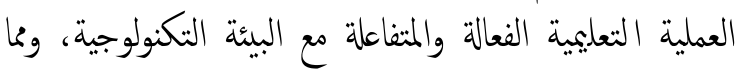

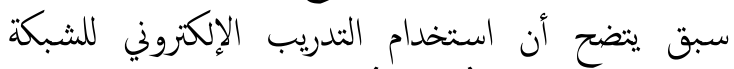

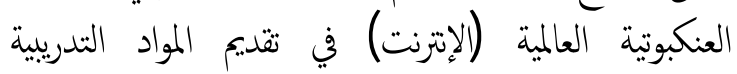

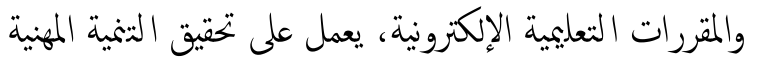

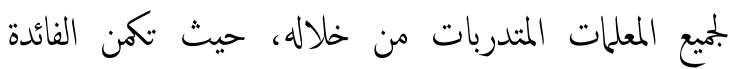
الأساسية من خلاله في التكلفة المنخفضة والكفاءة العالية في التدريب، وفيا يلي عرض لأهم عناصر التدريب الإلكنروني

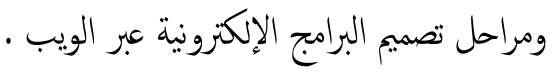

أولاأعناصر منظومة التدريب الإلكروني اللازمة لتدريب

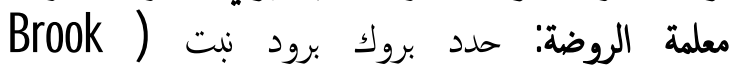

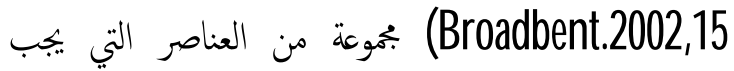
توافرها لتحقيق التدريب الإلكتروني عبر الإنترنت بشكل أكثر

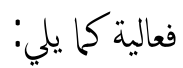

ا. المدرب!' حيث تمثل دوره في المتابعة والتوجيه والتقويم، وبناء الاختبارات الإلكترونية وتقييم المتدربين

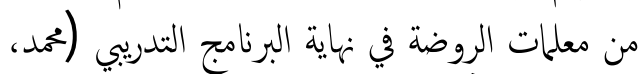

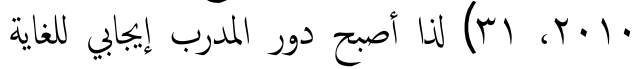
في إدارة عملية التدريب والتعلم. r, المتدربة (معلمة رياض الأطفال): يتيح التدريب الإنكتروني للطالبات المتدربات فرصة في المئي الدخول

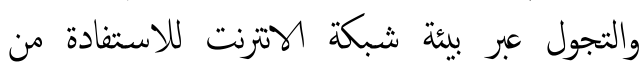
البرنامج التدربيي المراد تعليمه للمعلمة، واستخدام

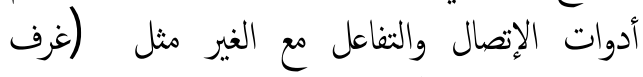

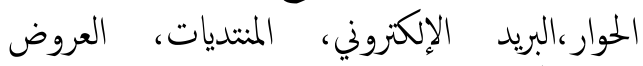

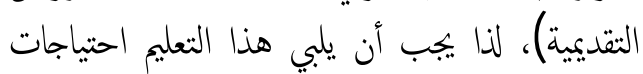
المتدربات من معلمات الروضة. r. البرنامج التدريبي (المتوى): إن المتوى الإلكتروني

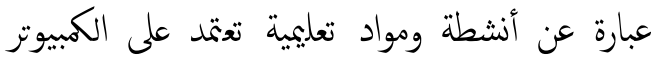

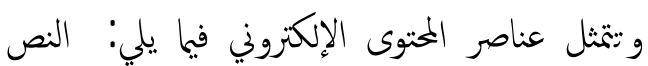
المكتوب، النصوص المسموعة والمؤثرات الصوتية، 
استخدام شبكة الويب في المدارس توفر للمتعلمين إمكانات

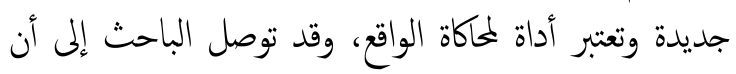

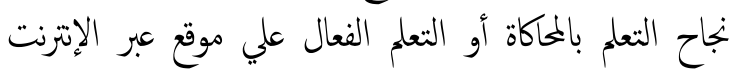

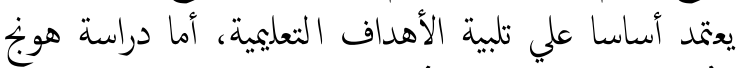
فتوصلت الدراسة إلى فاعلية (Hong, 2003, 49) استخدام الانترنت في التعليم كوسيلة تعليمية،وجود اتجاه إيجابي نحو استخدامه في التعليم.

المحور الثاني' المهارات التكنولوجية المراد تنميتها للطالبة المعلمة'

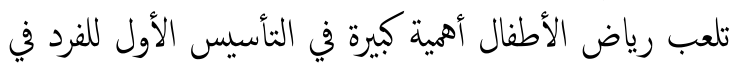

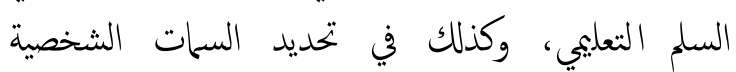
والإجتماعية والعلمية التي سيتمتع بها الفرد في حياته المستقبلية

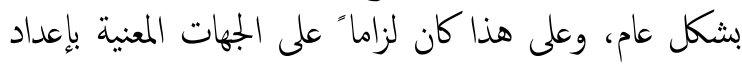

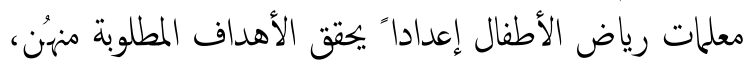

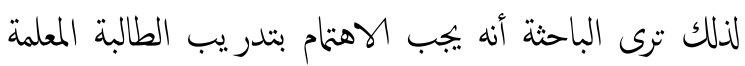
برياض الأطفال على بعض محارات استخدام التكنولوجيا

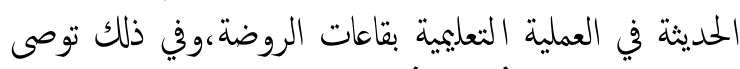

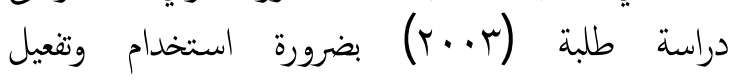

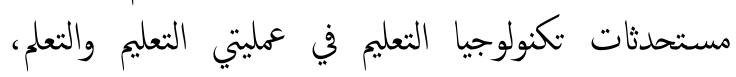

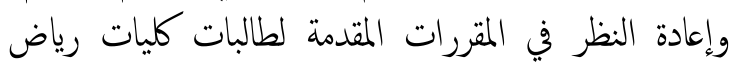

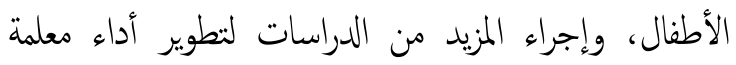

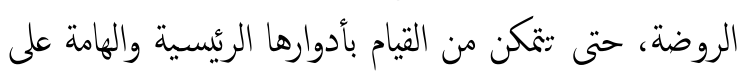

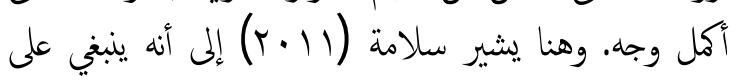

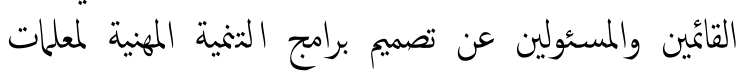

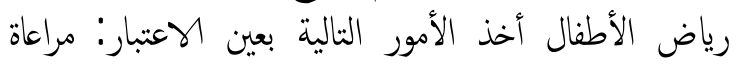

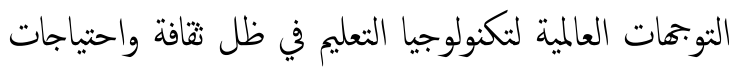

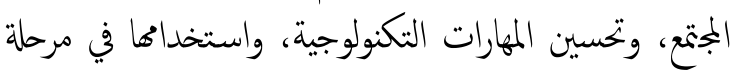
رياض الأطفال، وإدخال وتصميم معايير تكنولوجية للحكى على الماتل المارسات المهنية في ظل عصر التعلم الإلكتروني.

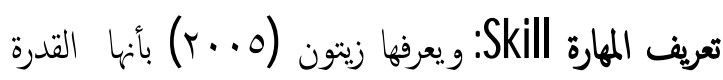

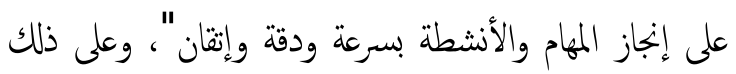

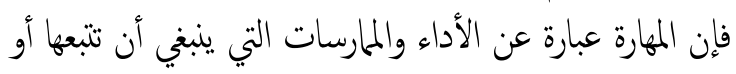

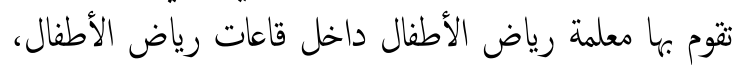

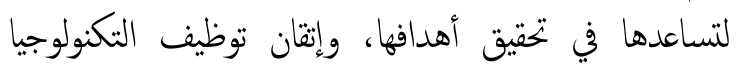
الحديثة بكفاءة عالية، من آجل تنمية محارات ومفاهيم أطفال

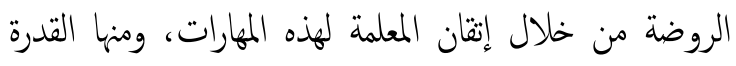

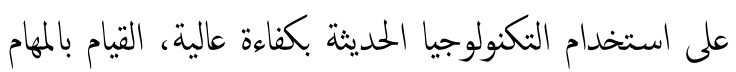

المحافظة على استمرار اهتمام المتعلم وإثارة دافعتيه لمواصلة

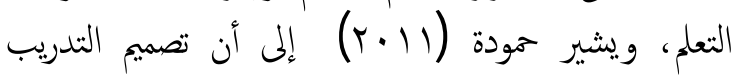

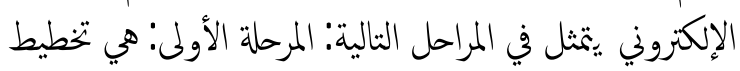
التدريب الإلكتروني وتتطلب تلك المرحلة تقدير الإحتياجات

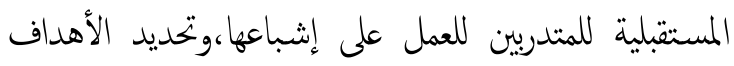
العامة والخاصة للتدريب ووضوحما ووضع الاستراتيجيات

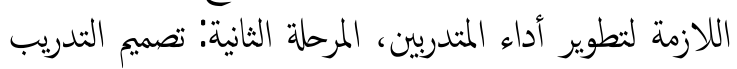

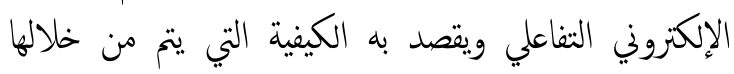

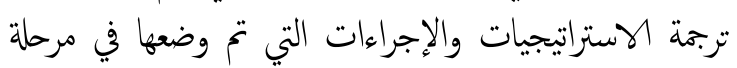
التخطيط لتحقيق أهداف الندريب بالإضافة إلى تصميم المنهج

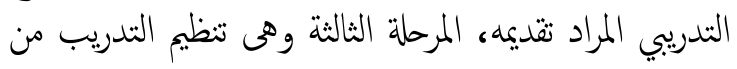

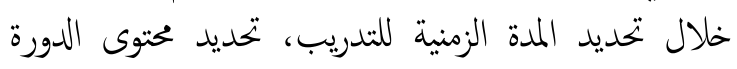

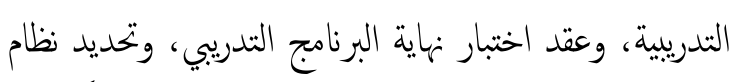

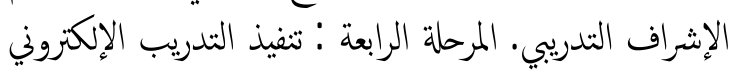

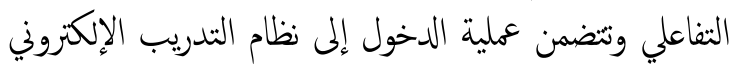

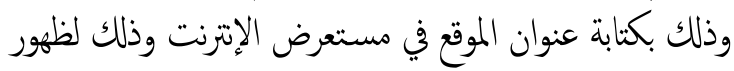

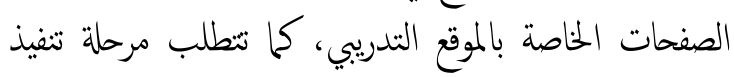

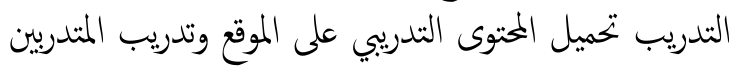

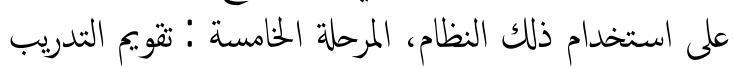

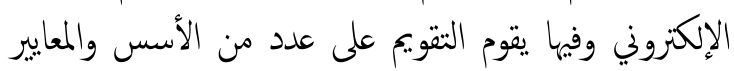

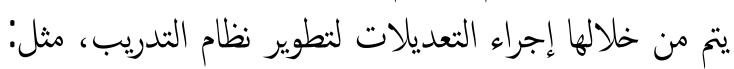

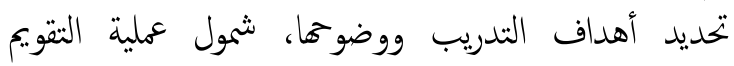
واستمرارها، ترابط عناصر منظومة الندريب واتساقها، تكامل

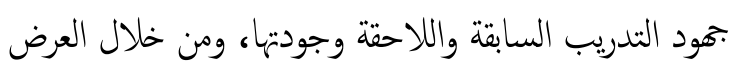

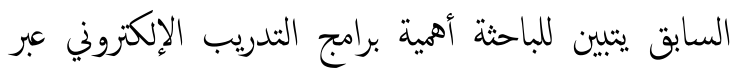
الإترنت.

ومما سبق يتضح أن من أهم معايير بناء صفحات الويب: كما

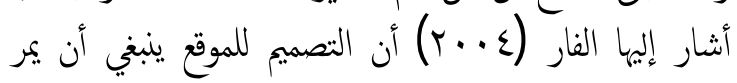

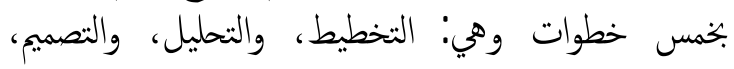

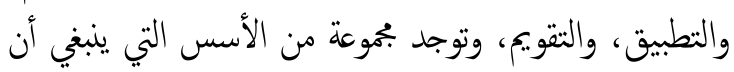

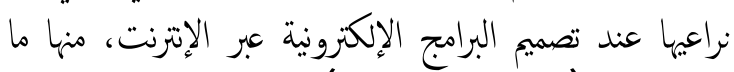

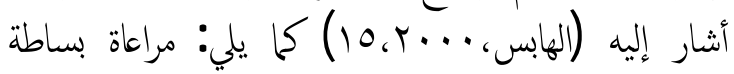

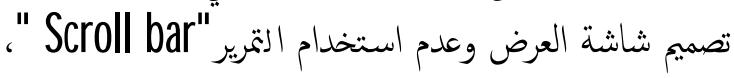

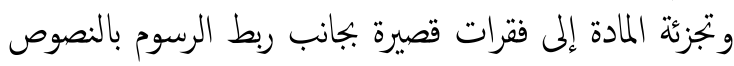

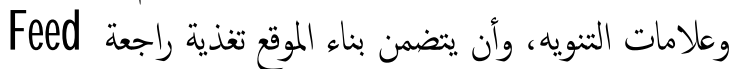

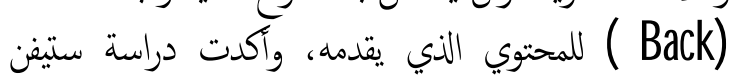
شميدت (Stephen Schmidt, 2003, 47) على أن 
ومعارفه، فلم يعد المعلم اليوم مجرد ناقل للمعلومات والمعرفة بل

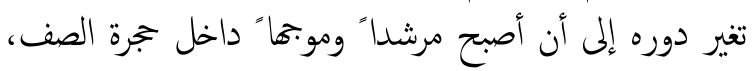

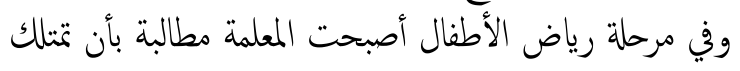

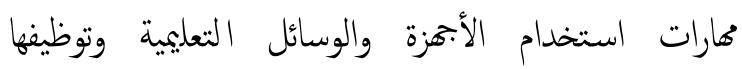

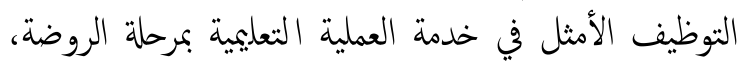

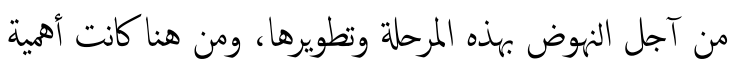

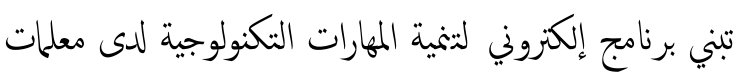

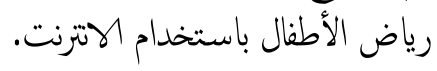

\section{مشكلة البحث}

يتميز العصر الحالي بالعديد من التحديات التي يوابهها الطالب

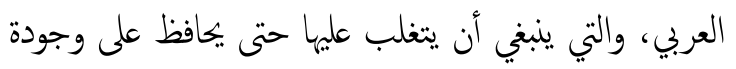

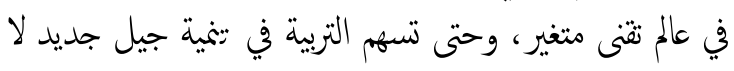

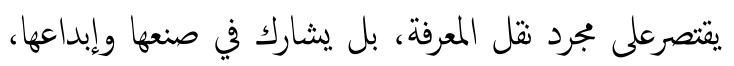
وهذا الذي يسعى إليه البحث العلمي بصفة عامة والباحثين بئن

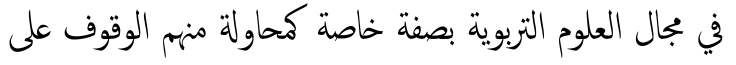

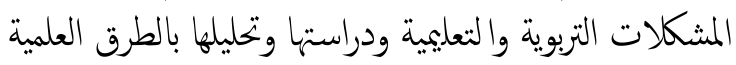

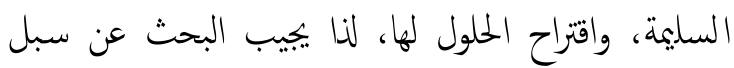

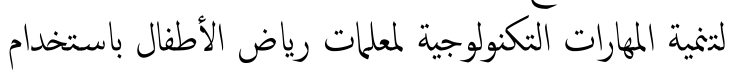

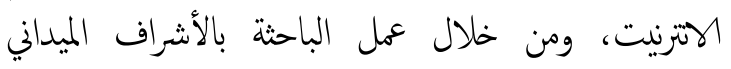

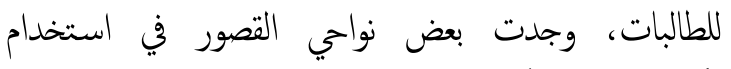

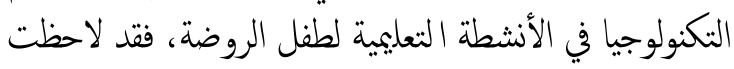
الباحثة ما يلي: - مئي

1. قصور لدى الطالبة المعلمة برياض الأطفال في كيفية

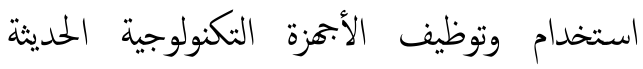
وتوظيفها التوظيف الأمثل على الرغخيف من توافرها بالروضة.

r. في حدود علم الباحثة لا يوجد برامج إلكترونية عبر

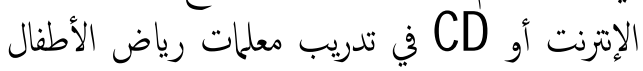

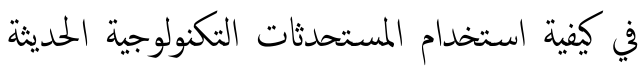
في العملية التعليمية.

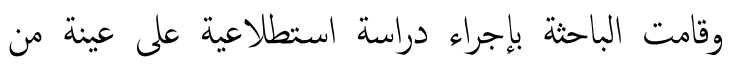

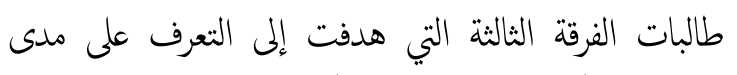

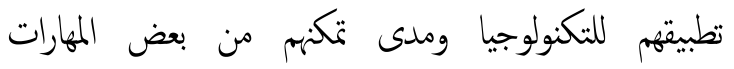
التكنولوجية في العملية التعليمية فأظهرت نتائُ الدراسة

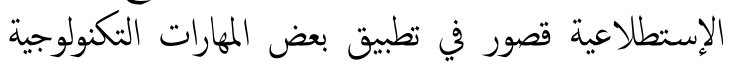

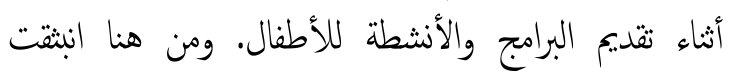

المطلوبة بسرعة عالية. والمهارة في البحث الحالي تتمثل في قدرة الطالبة المعلمة على توظيف كافة المستحدثات التكنولوجية داخل قاعات رياض الأطفال بسهولة ويسر، وذلك من خلم خلال

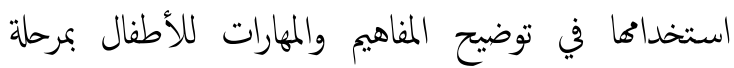

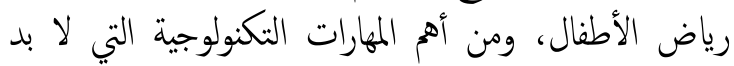

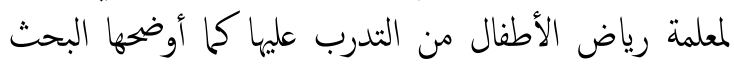

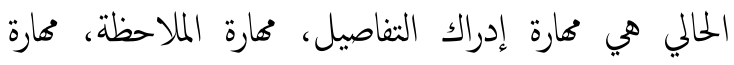
التصميم، محارة الحساسية للمشكلات.

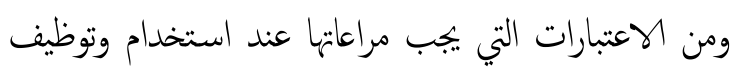

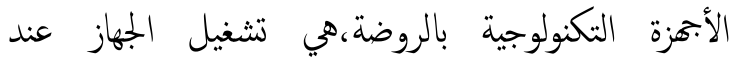

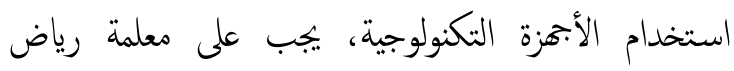

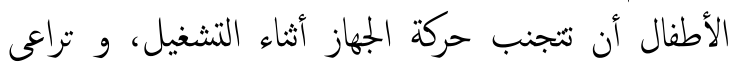

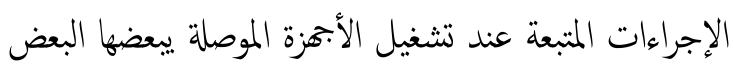

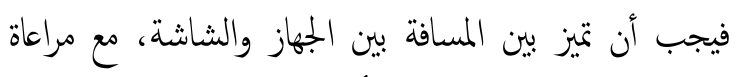
مكان وقوف المعلمة وجلوس الأطفال، مرحلة الإعداد وهي أن

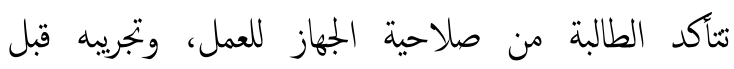

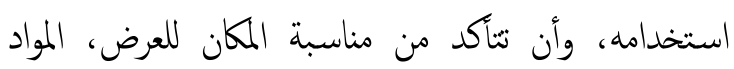
التعليمية ويجب أن تراعي معلمة رياض الأطفال وضع المواد

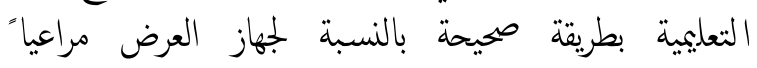

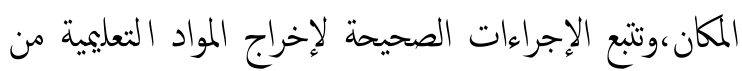

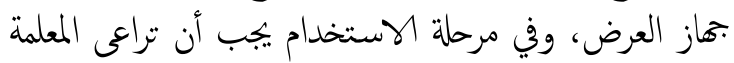
ضبط مساحة الصورة على الشاشة بالتحكم في وضع الجهاز والشاشة حتى تكون الصورة مناسبة لحجم المشاهدين.

فرضت المتطلبات السابقة نوعاء جديدا" من التعليم، وكان لابد

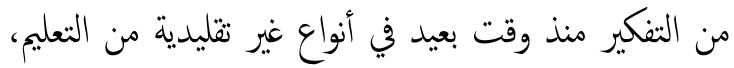

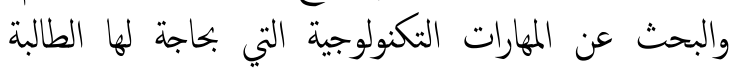

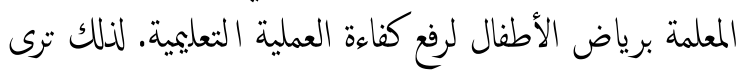

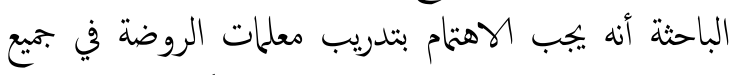

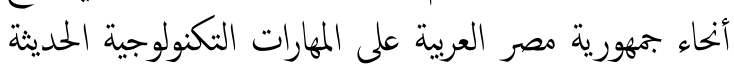

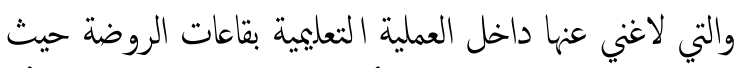

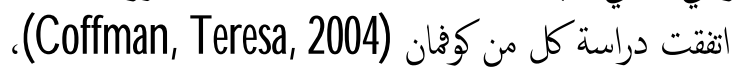

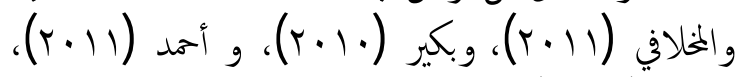

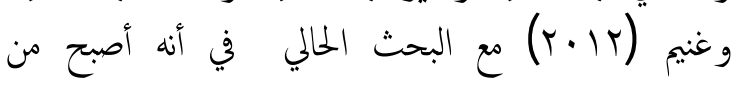

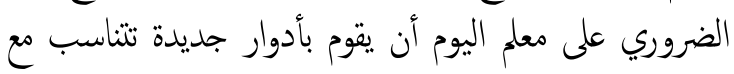

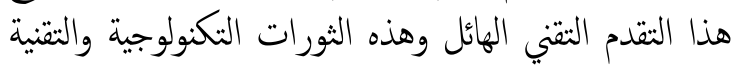

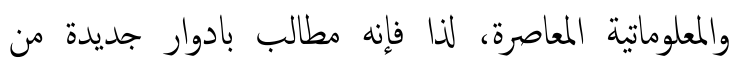
خلالها يككن النهوض بمستواه علميا وتربويا وتنمية محاراته 
حدود زمنية، تطبيق البرنامج الإلكتروني عبر الويب على مدار شهرين.

حدود بشرية، تتمثل في عينه من الطالبات المعلمات بالفرقة الثالثة بكلية رياض الأطفال - جامعة القاهرة.

\section{مصطلحات البحث}

التدريب الإلكروني : هو نظام تدريبي بين متدربين ومدربين

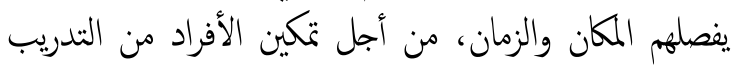

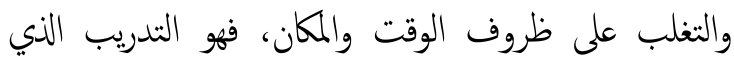

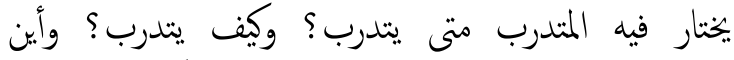

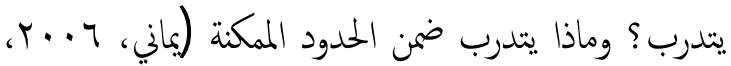
(1)

البرنامج الإلكنووني: تقديم وحدات تدريبية نظرية وعملية إلى

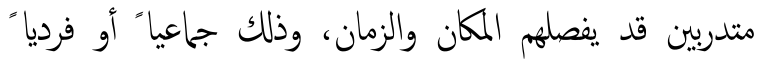
باستخدام أنظمة خاصة للتدريب عبر شبكة الإنترنت لتحقيق

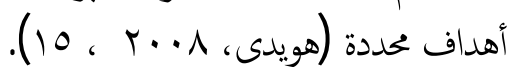

التعريف الاجرائى للبرنامج الإلكروني: هو العملية التي يتم

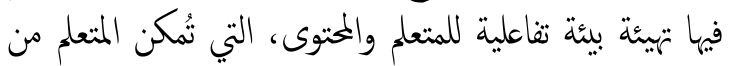

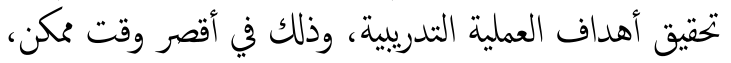

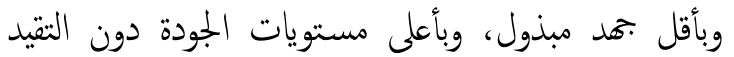

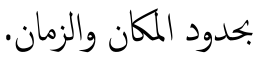

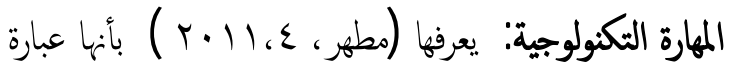
عن أسلوب مبرمج في التربية مهدف إلى زيادة فعالية محاور

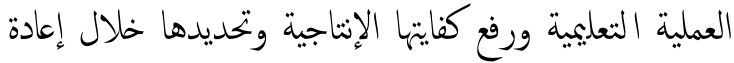
تخطيطها و تنظيمها وتنفيذها. التعريف الاجرائى المهارة التكنولوجية' هي امتلاك الفرد

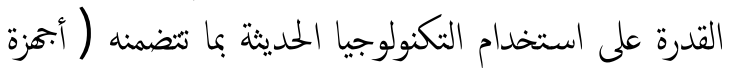

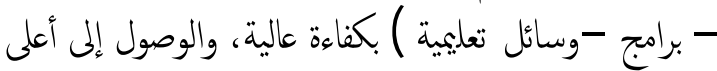

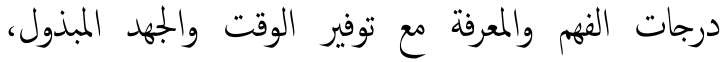
وتحويل البيئة التعليمية بقاعات رياض الأطفال إلى بلى بيئة فعالة

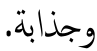

شبكة الإترنت (الويب) Internet! تعرفها جايس و هولمز

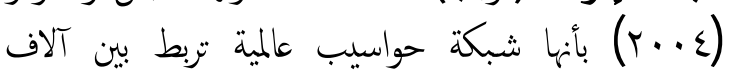
الشبكات الصغيرة في نظام يتألف من مزودات (Servers) تدع مستندات ذات تنسيق خاص. وتعرفها الباحثة إجرائيا

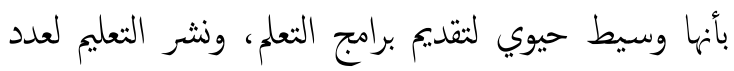

المشكلة ونبعت فكرة البحث الحلالي،في أن يكون التدريب

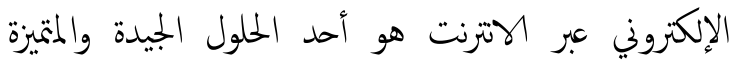

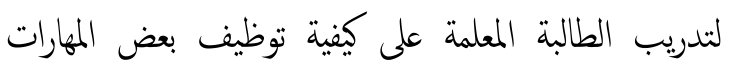

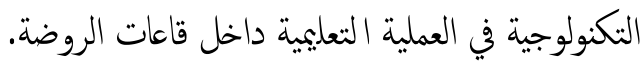

وبالتالي تتبلور مشكلة البحث في السؤال التالي' ما مدى الباى

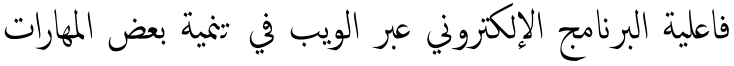

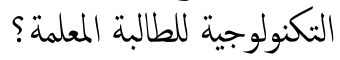

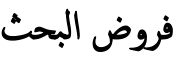

ا- توجد فروق دالة إحصائياً بين متوسطات درجات

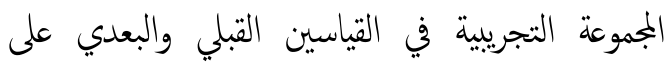

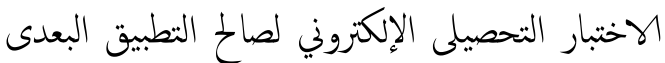
المجموعة التجريبية. r- توجد فروق دالة إحصائياً بين متوسطات درجات

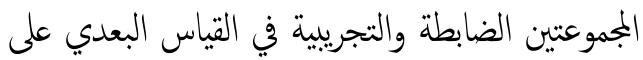

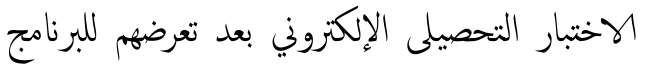
الإلكنروني لصاح المجموعة النجريبة.

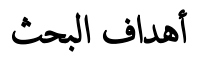
بهدف البحث الحالي تحقيق ما يلى: 1. تحديد بعض المهارات التكنولوجية للطالبة المعلمة

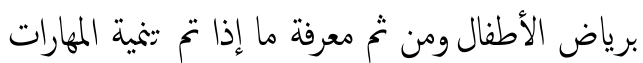
عبر توظيف البرنامج الإلكتروني عبر الويب.

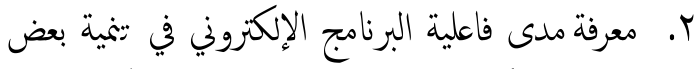
المهارات التكنولوجية لدى معلمات رياض الأطفال.

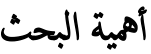

ا. رفع كفاءة حمارات الطالبة المعلمة على استخدام التكنولوجيا من خلال برنامج التدريب الإلكروني. r. زيادة كفاءة المؤسسات التعليمية من خلال التعلم الإلكنروني عن بعد في ظل نظام تكنولوجيا المعلومات.

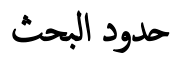

يلتزم البحث الحالي بالحدود التالية.

حدود جغرافية' أقتصر البحث على الطالبات المعلمات (بالفرقة الثالثة) بكلية رياض الأطفال -جامعة القاهرة. 


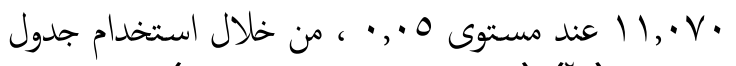

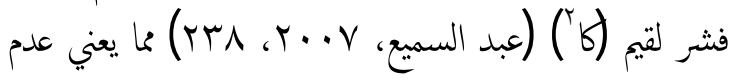

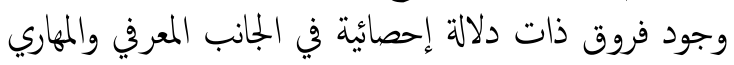

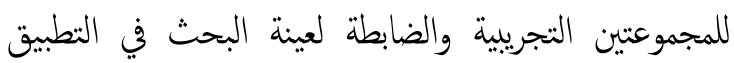

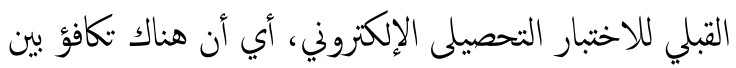

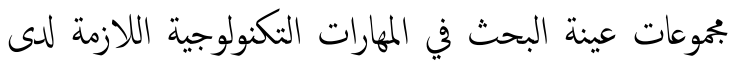
الطالبات المعلمات.

$$
\text { أدوات البحث }
$$

ا ب برنامج إلكتروني لتنمية بعض المهارات التكنولوجية لدى الطالبة المعلمة برياض الأطفال.

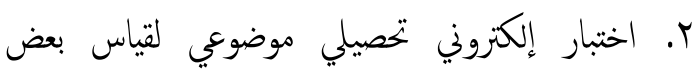
المهارات التكنولوجية للطالبة المعلمة برياض الأطفال.

أولاا: البرنامج الإلكروني لتنمية بعض المهارات النكنولوجية اللطالبة المعلمة برياض الأطفال:

البرنامج الإلكموني' يعرف إجرائيا في هذه الدراسة بأنه عبارة عن صفحة رئسية وعدة صفحات تم ربطها معا من خلال النصوص الفائقة؛ لتقديم برنامج وإلكتروني تعليمي لتحقيق صنيق

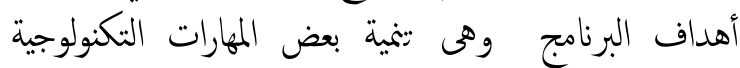
للطالبة المعلمة، ويقدم من خلال بيئة تعليم تفاعلية. فلسفة البرنامج' اعتمت الباحثة في بناء التصميم التعليمي

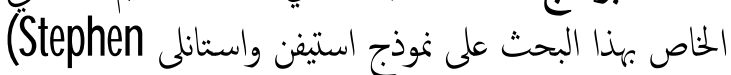
d Stanley, 2001) للتصميم التعليمي الخاص بالبحث الحالي وقد حرصت الباحثة في تصميم وإنتاج البرنامج الإنكتروني الذى سيقدم إلى الى الى

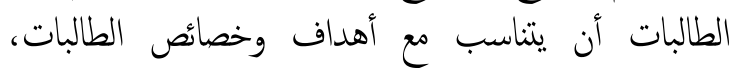
والإمكانات المتاحة وظروف التعلم، وتضمن النموذج المراحل والخطوات اللازمة لعمليتي التصميم والإنتاجن

أسس وخطوات تصميم وبناء البرنامج الإلكتروني عبر الويب: مرت عملية تصميم وبناء البرنامج بالخطوات الخوات التالية. التخطيط' بعـد تحديد أهـداف البرنامج، روعي أن تكون

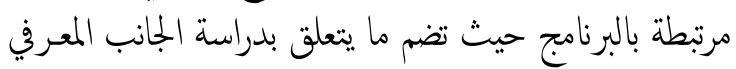
والمهارى الخاص ببعض الأبزة التكنولوجية.

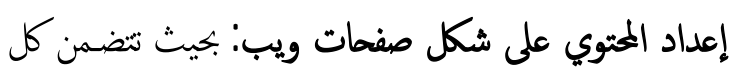

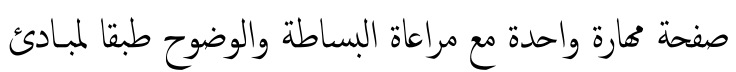
صفحات الويب التي سبق الحديث عنها.
كبير من المتعلمين، وإتاحة المعرفة من خلال إزالة حواجز

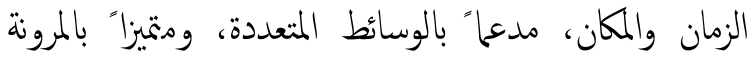
والتفاعلية.

الطريقة والإجراءات

منهج البحث

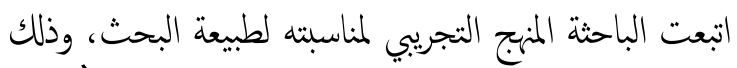

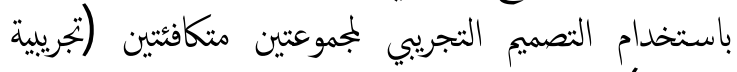

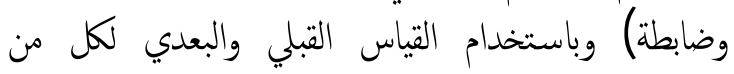

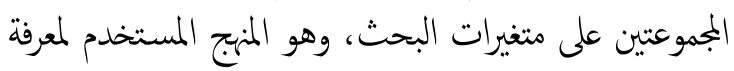

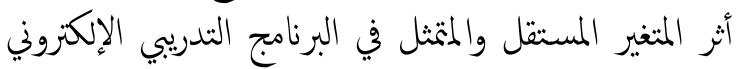

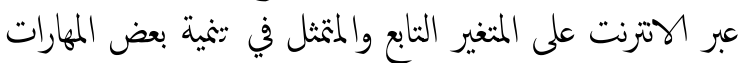
التكنولوجية لمعلمات رياض الأطفال .

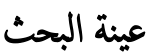

تكونت عينة البحث من •ج طالبة من الفرقة الثالثة بكلية

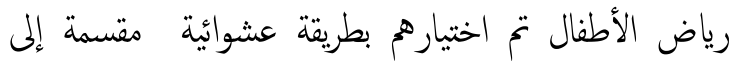

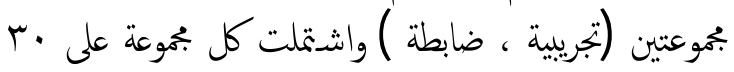

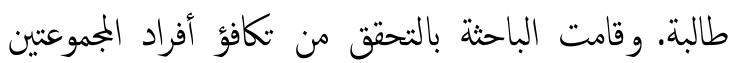

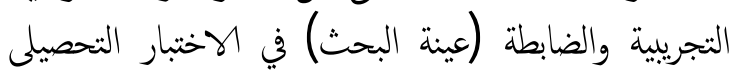

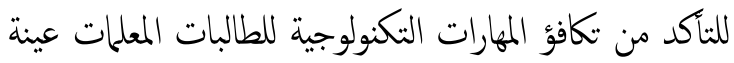

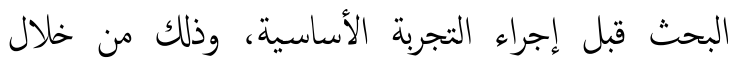

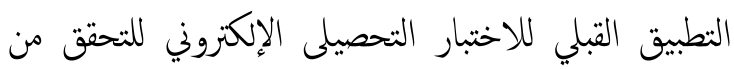

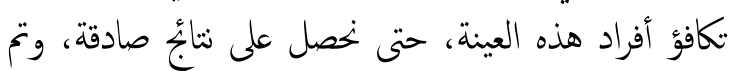

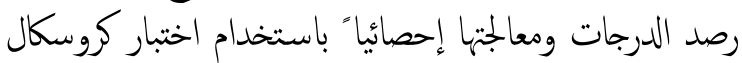
واليس (Kruskal \&Wallis Test) وتنتخص نتائو المعالجة فيما يلي: - المين

\section{جدول 1}

ككفو أفراد المجموعتين التجريبية والضابطة في الاختبار التحصيلي

\begin{tabular}{|c|c|c|c|c|c|}
\hline \multicolumn{6}{|c|}{ في التطبيق القبلي } \\
\hline الدلالة & $\sqrt{6}$ & درجة & متوسط & العدد & الجمموعة \\
\hline & & الحرية & الرتب & & \\
\hline & & & $r, v$. & r. & التجريبية \\
\hline 0,990 & .9 & 0 & $r V, \lambda$. & $r$. & الضابطة \\
\hline
\end{tabular}

يوضح جدول ا أن قيمة (لاكا) غير دالة إحصائياً بالنسبة

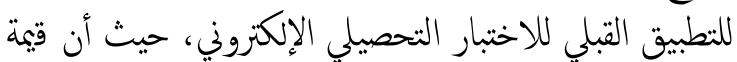

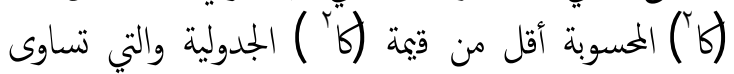


المعروض وجعلها آكثر فائدة ودقة، وإضافة تفصيلات جديدة

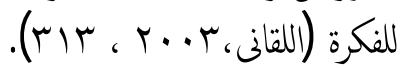
ثانيا': محارة الملاحظة' وهى محارة التدقيق في الأجزة والبرامج

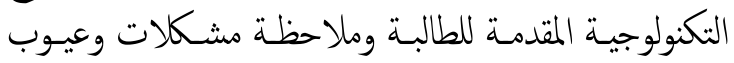

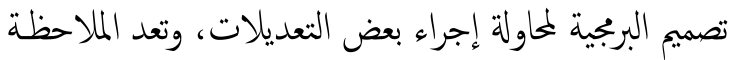

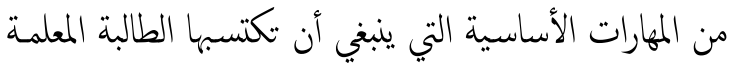

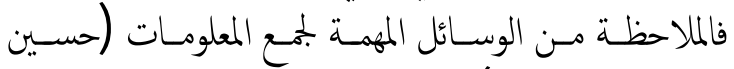

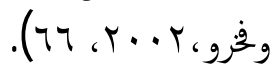

ثالثا' محارة التصميم' إن تصميم البرجيـات هو عمليـة إبـاع ،

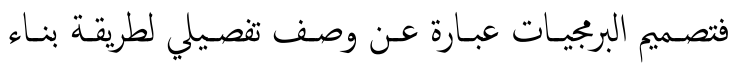

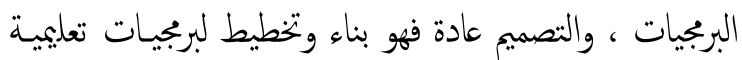

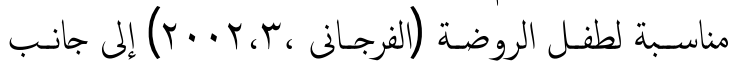

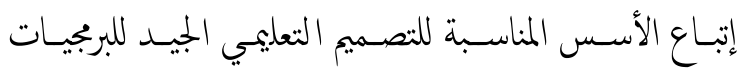
التعليمية ومعرفة الإعداد الجيد لسيناريو البرجية. رابعا' محارة الحساسية للمشكلات' وهى القدرة على التعرف

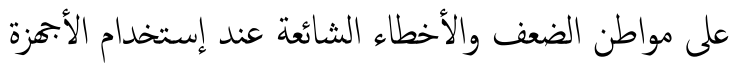

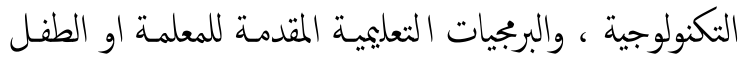

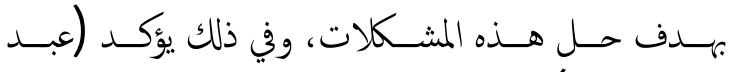

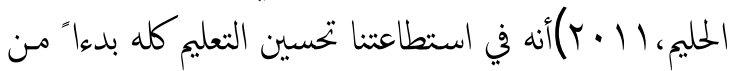

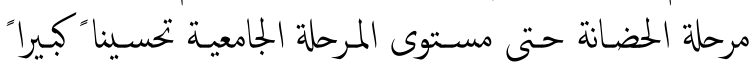

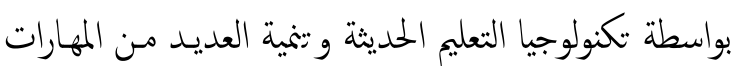

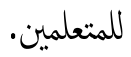
الإجـراءات التطبيقيـة للبرنامج الإكتروني' قامت الباحثة

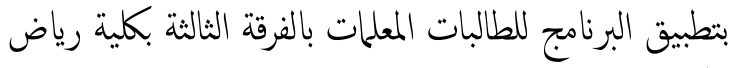

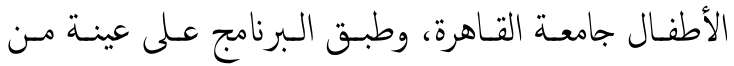

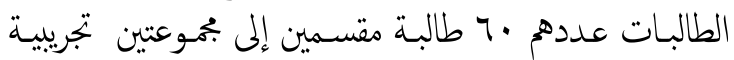

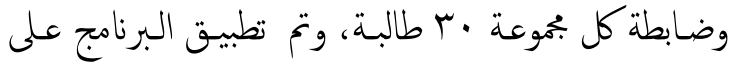

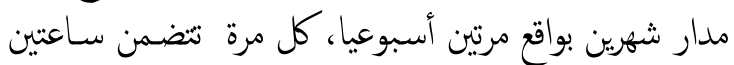

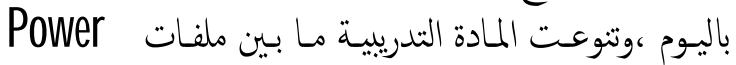

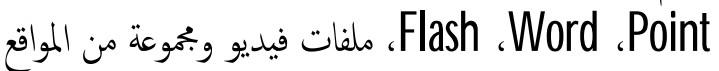
المرتبطة بالمادة التدريبية على جروب تدريب تكنولوجيا التعليم

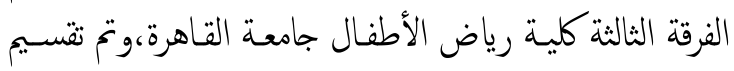

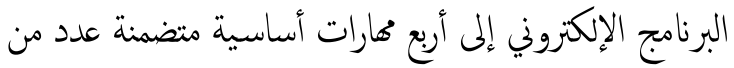

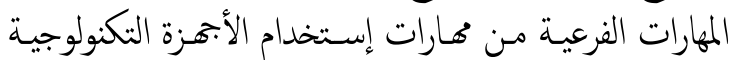

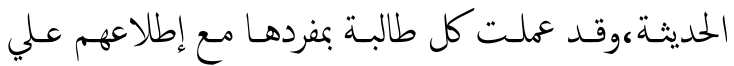

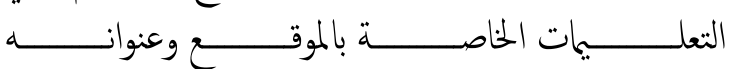

تصميم صفحات المحتوي' وفي هـذه المرحلة تم مراعاة القواعد

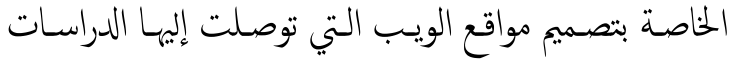

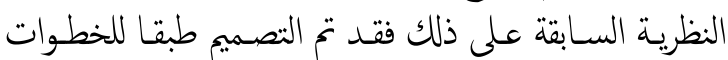
التالية:

- تحطيط وابجة الموقع: وفيها تم تصميم الصورة المبدئية

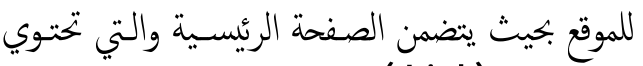
على ارتباط (Link) للانتقال إلي الصفحات الرئيسية لمنية

$$
\text { عند التصفح. }
$$

- - صور للأجحزة التكنولوجية: رابط يعطي صور مختلفة لأنواع أبهزة العروض الضوئة التي يتضمنها البرنامج. - خطوات اسـتخدام بعض الأجهزة التكنولوجيـة التي

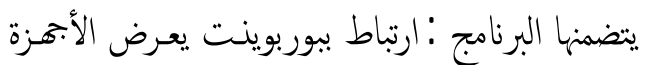
بالضغط على صورة الجهاز تقتح شاثة تشرح مكونات بناته وخطوات تشغيله ومميزات إستختحدامة وعيوبه وكيفية

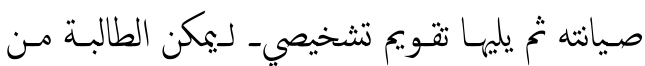

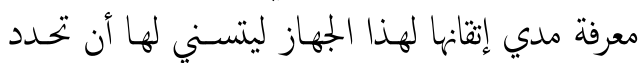

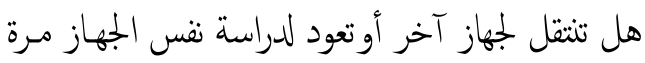
أخرى. - مل تئل

المواد التعليمية اللازمة لتصميم الموقعi' حيث استخدمت الباحثة

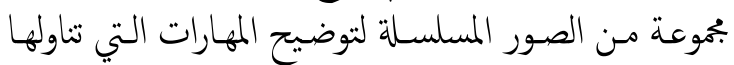

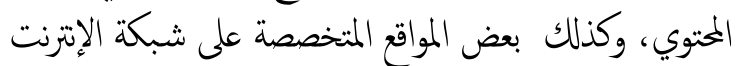

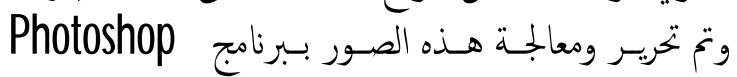
Adobe

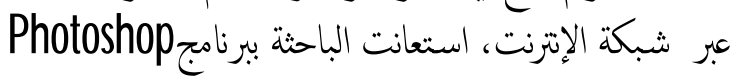

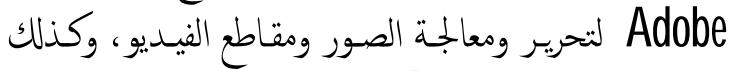
برنامج Dream weaver وذلك للقطات المضيئة وتم تصميم

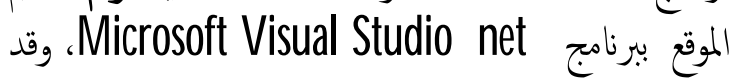
روعي استخدام اللغـة اللفظيـة وغير اللفظيـة عنــ صياغة

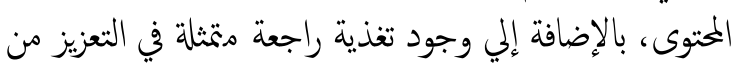

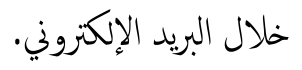

ومن أهم المهارات التكنولوجية التى تم توظيفها في البحث الحالي:

أولا' محارة إدراك التفاصيل' وهى محارة تحتابحا الطالبة المعلمة

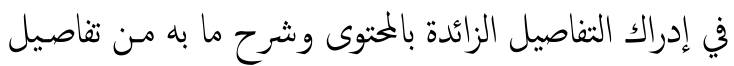

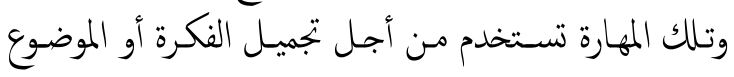


بأهداف تنمية بعض المهارات التكنولوجية للطالبة المعلمة، وقد

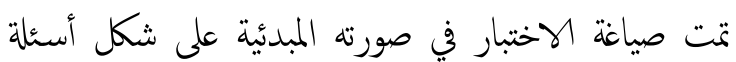

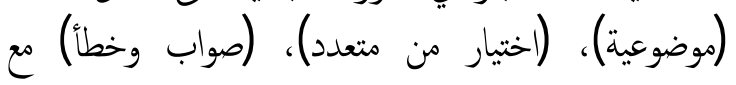

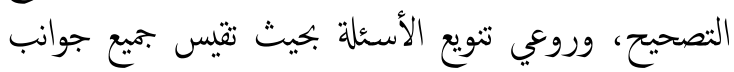

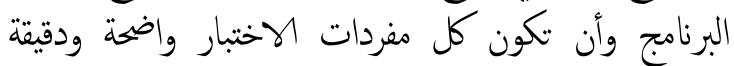
وصيغت بأسلوب سهل وواضح'

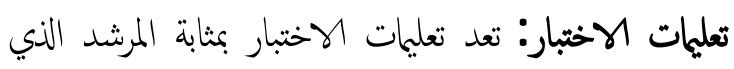

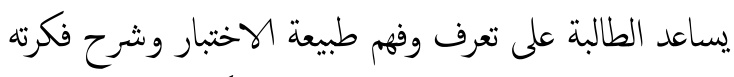

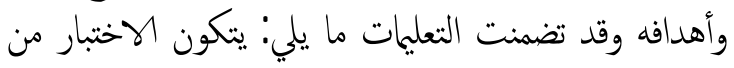

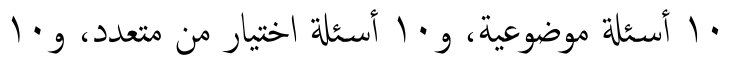
أسئلة صواب وخطأ مع التصحيح والمطلوب: 1. قراءة كل سؤال بعناية ودقة قبل الإجابة.

r. الإجابة عن الأسئلة باختيار واحد فقط أو وضع علامة واحدة فقط.

r. الدرجة النهائية للاختبار · ب درجة واحدة لكل سؤال.

صدق الاختبار: للتأكد من صدق الاختبار تم عرضه بعد

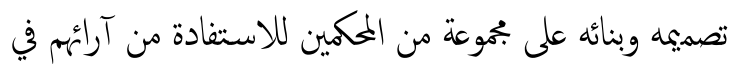

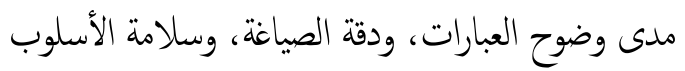

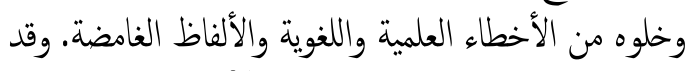

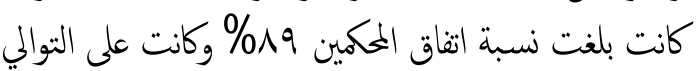

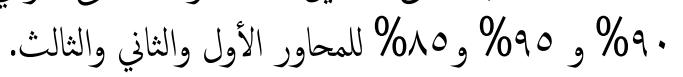

ثبات الاختبار: والمقصود بثبات الاختبار هو إعطاء نفس

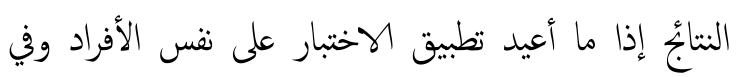

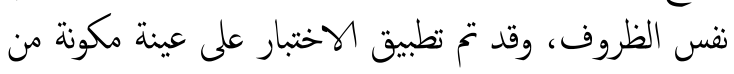

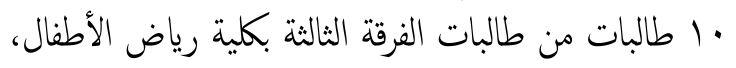

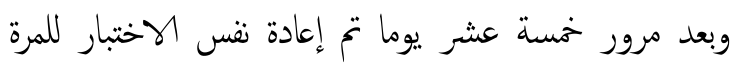

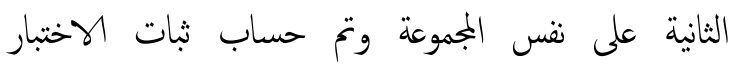
وباستخدام معادلة بير سون وكان معامل الثبات وهذه النسبة مرتفعة ومقبولة وتعبر عن ثبات الاختبارن زمن تطبيق الاختبارن' تم حساب الفترة الزمنية التي استغرقها

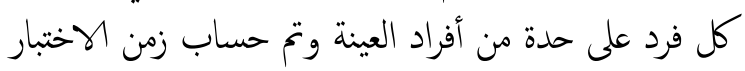

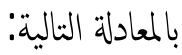

\section{زمن إجابة الطالب الأول † زمن إجابة الطالب الأخير}

$r$ https:// www.facebook.com/groups/66

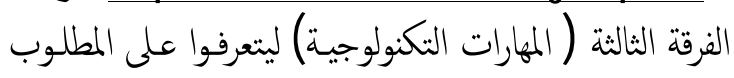

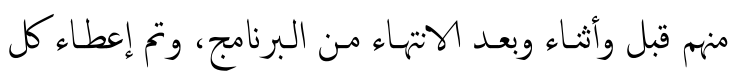

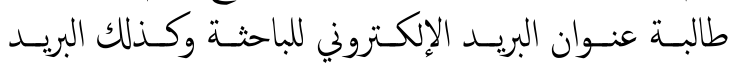

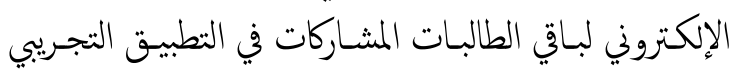

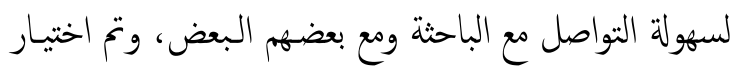

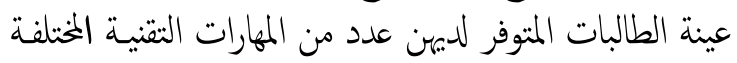

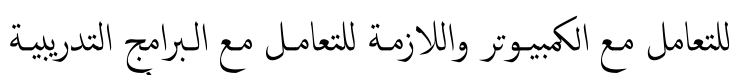

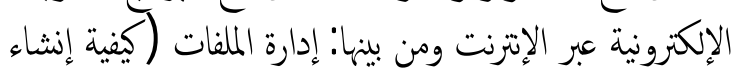

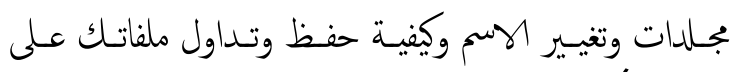

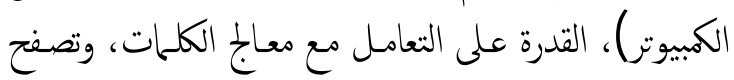

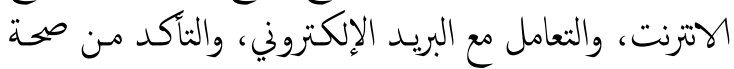

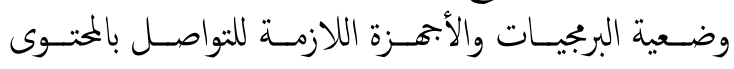

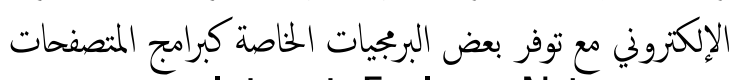

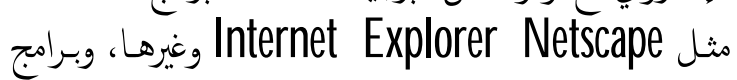

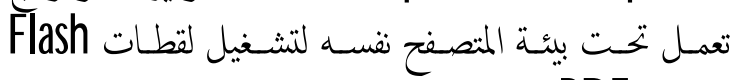
وملفات PDF ولقطات الفيديو والصوت وغيرها.

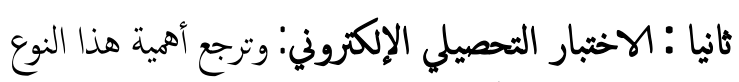

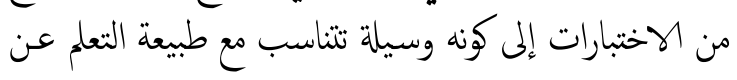

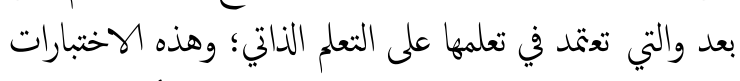

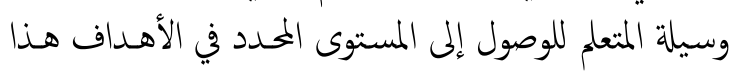

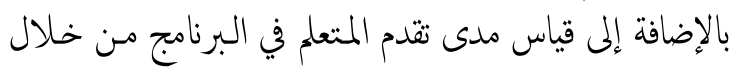

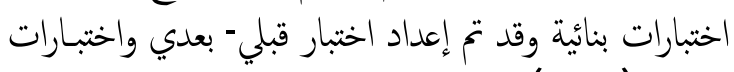

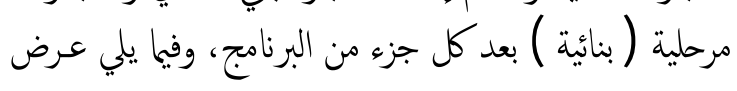

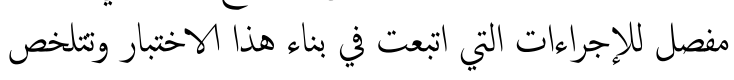
فيما يلي: أهداف الاختبارا: هيدف الوختبار التحصيلي إلى:

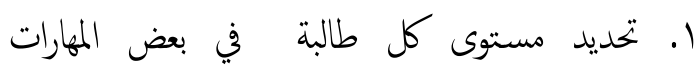
التكنولوجية من خلال موقع الإنترنت.

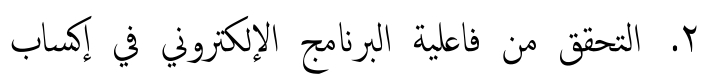

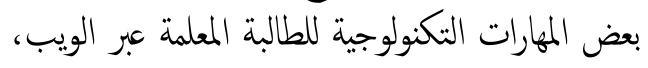

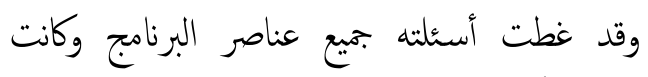

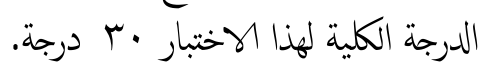

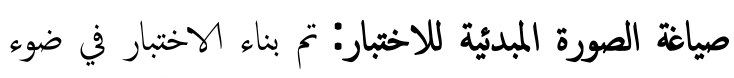

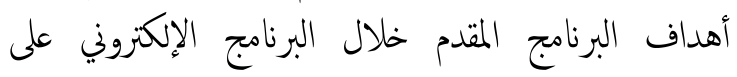
الإنترنت حيث ارتبطت مفردات الاختبار ارتباطا وثيقاً الإكنا 
الجدوليـة T7, T وهي قيمـة دالة إحصائيا وهـذا يثبـت فاعليـة

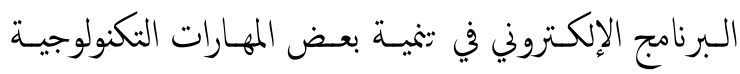
للطالبة المعلمة الإنكتر

وتنفق هذه النتيجة مع نتائُ دراسة نوح وتشا (Noh \& Cha, 2004)

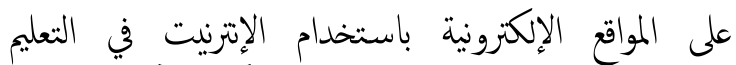

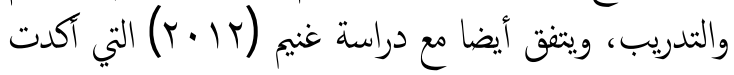

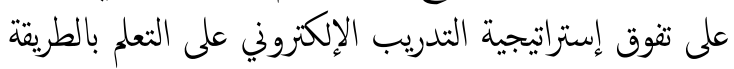

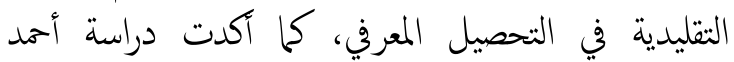

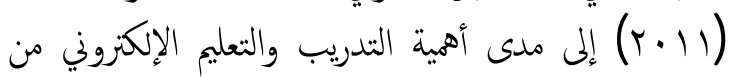

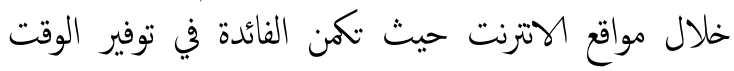
والجهد مع الكفاءة العالية للتدريب الإنكنروني.

\section{نتائج التحقق من صحة فروض البحث}

التحقق من الفرض الأول'توجد فروق دالة إحصائيا" بين

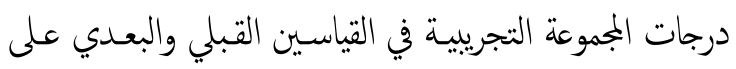

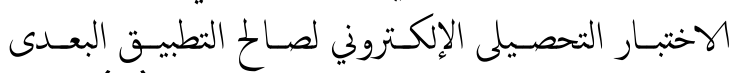

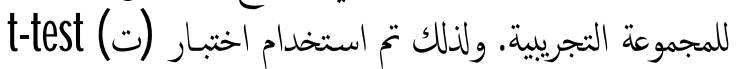

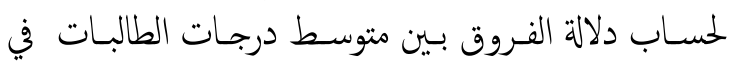
الاختبار الإلكنروني للمجموعة الضابطة والمجموعة التجريبية.

$$
\text { جدول ب يوضح النتائُ، }
$$

يتبــن مسن جـدول ب ارتفـاع متوسـطات درجـات طالبـات

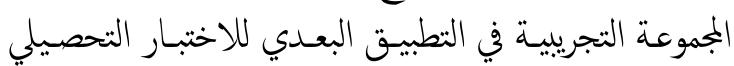

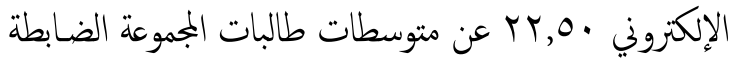

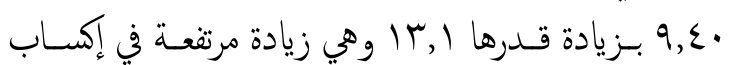

وكان الزمن الذي استغرقته أول طالبة هب دقيقة وآخر

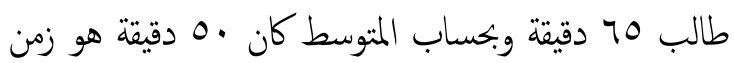
الاختبار الب التحليل الإحصائي: للإجابة عن أسئلة البحث واختبار صحة

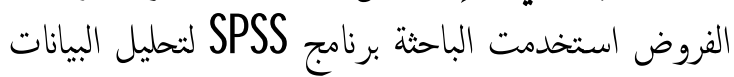
إحصائيا.

\section{النتاجُج ومناقشتها}

وللإجابة عن سؤال البحث مـامـدى فاعلية البرنامج

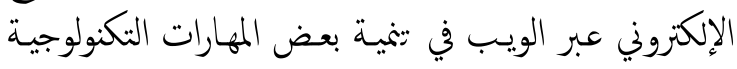

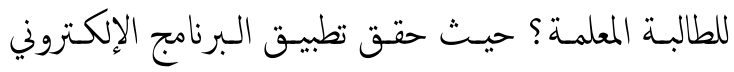
فاعلية بالغة في تقديم بعض المهارات التكنولوجية المراد تنميتها

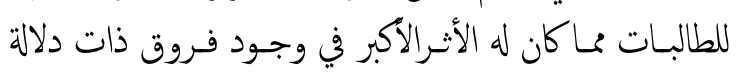

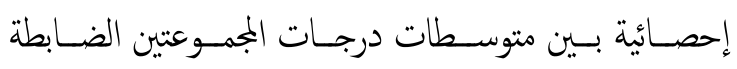

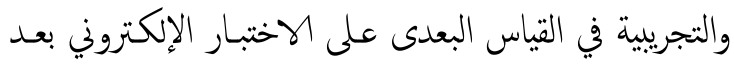

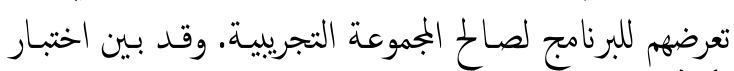

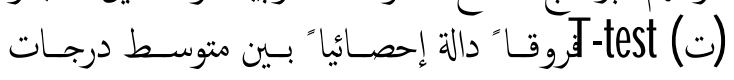
الطالبات في الاختبار الإلكتروني القبلي والاختبار الإلكتروني

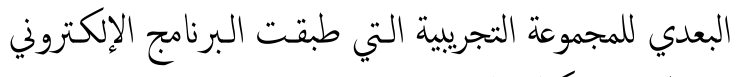

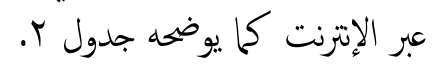
ويتضح من جدول r ارتفاع متوسطات درجات الطالبات في

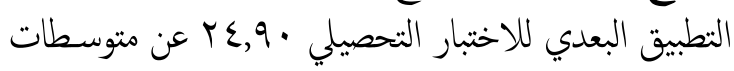

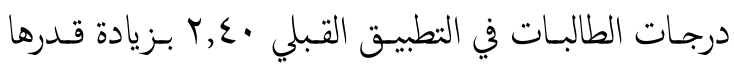

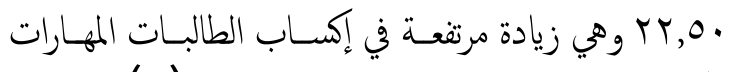

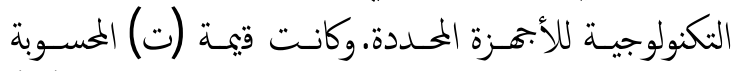

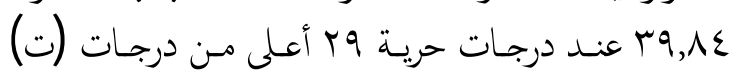

جدول r

المتوسط والانحراف المعياري وقية ت لدلالة الفروق بين متوسط درجات الطالبات في الاختبار التحصيلي الإلكتوني

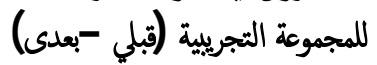

\begin{tabular}{|c|c|c|c|c|c|c|}
\hline مستوي الدلالة & قيمة (ت) & درجات الحرية & الانحراف المعياري & المتوسط & العدد & العينة \\
\hline., .1 & $r q, \wedge \varepsilon$ & rq & $1, r T$ & $r, \varepsilon$. & & الاختبار القبلي \\
\hline & & & $r, \lambda$. & $r \varepsilon, q$. & $r$. & الاختبار البعدي \\
\hline
\end{tabular}

جدول r

للحساب دلالة الفروق بين متوسط درجات الطالبات في الاختبار التحصيلي الإلكروني البعدي للمجموعة الضابطة والمجموعة التجريبية

\begin{tabular}{|c|c|c|c|c|c|c|}
\hline مستوي الدلالة & قيمة (ت) & درجات الحرية & الانحراف المعياري & المتوسط & العدد & المجموعة \\
\hline$\cdot, \cdot 1$ & TV, YA & rq & $r, r V$ & $q, \varepsilon$. & $r$. & الضابطة \\
\hline & & & $r_{1} \cdot q$ & Tr,O. & $r$. & التجرييية \\
\hline
\end{tabular}


للأبهزة والبرامج النكنولوجية (r) (r) عن متوسطات

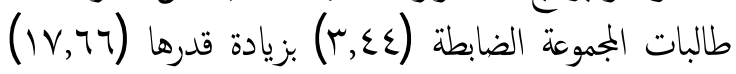

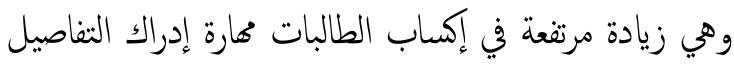

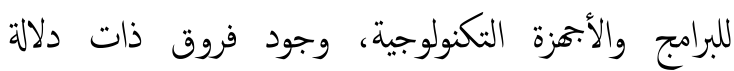

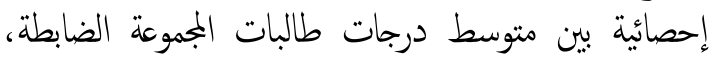

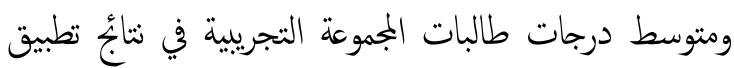

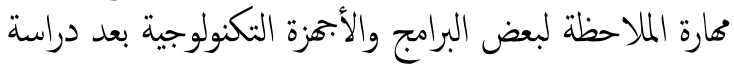
البرنامج عند مستوي دلالة ا •, •• لصالح المجموعة التجريبية

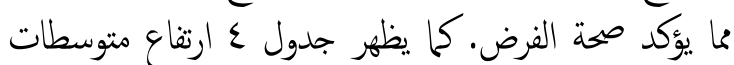
درجات طالبات المجموعة النجريبة في التطبيق البعدي لمهارات

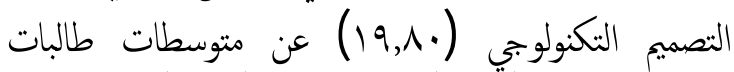

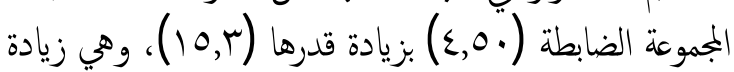

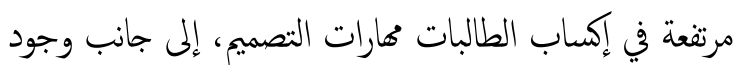

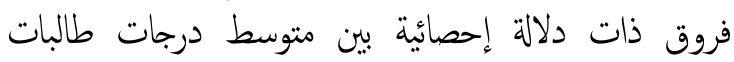
المجموعة الضابطة ومتوسط درجات طالبات المجموعة التجريبية

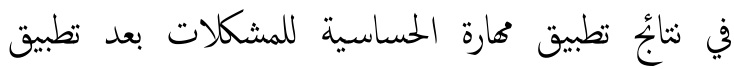

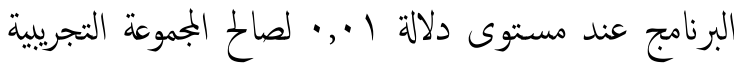

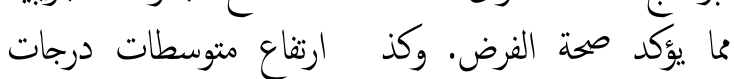

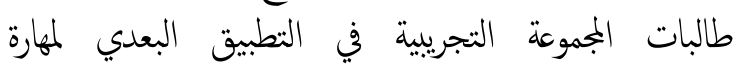

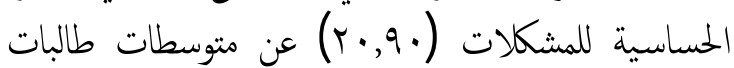

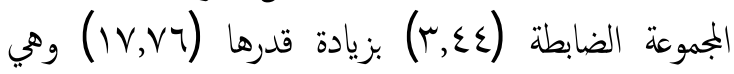
زيادة مرتفعة في إكساب الطالبات محارة الحساسية ل المشكلات.

ويرجع ذلك إلى البرنامج الإلكتروني وما تضمنه من مادة

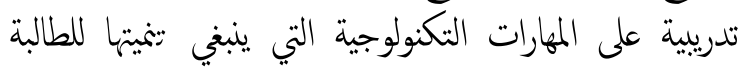

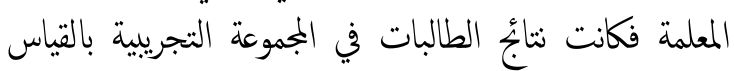

الطالبات المهارات التكنولوجية للأجهزة، وجود فروق دالة

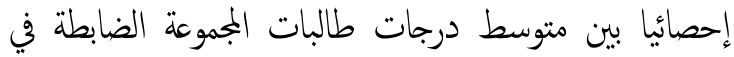

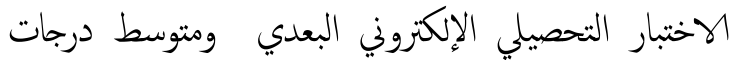
طالبات المجموعة التجريبية في الاختبار التحصيلي الإلكنروني

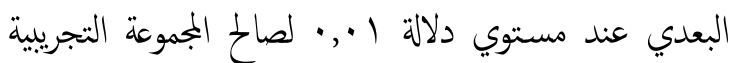

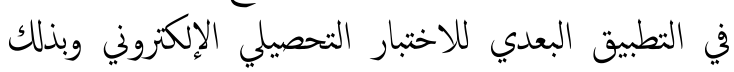

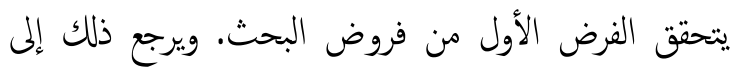

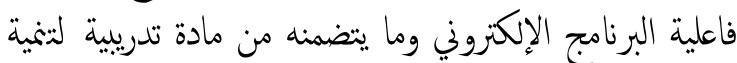

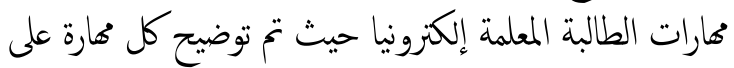

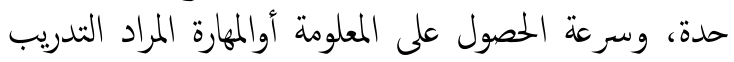

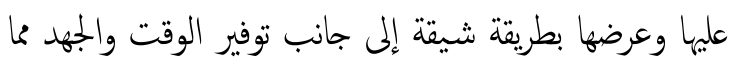

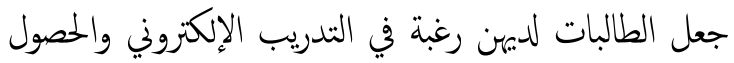

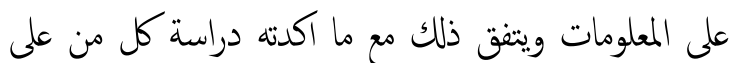

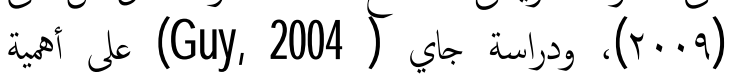

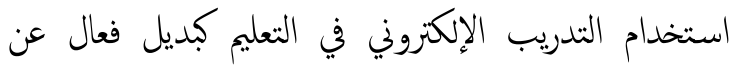

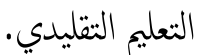

التحقق من الفرض الثاني': توجد فروق دالة إحصائياً بين

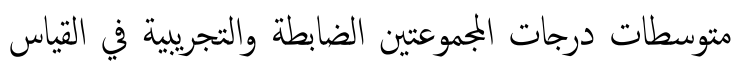

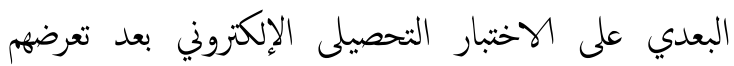

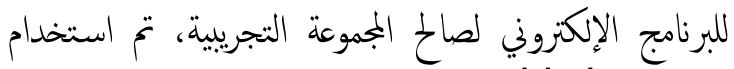

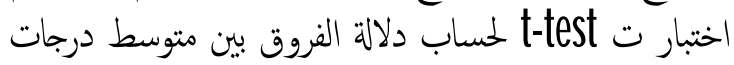

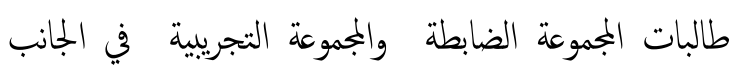

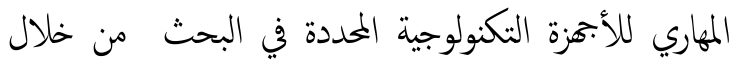

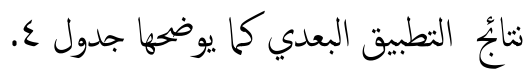
يتضح من جدول ع ارتفاع متوسطات درجات طالبات

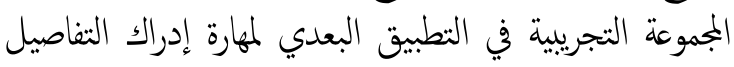

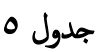

المتوسطات الحسابية والاخرافات المعيارية وقيهة ت لدلالة الفروق بين الجمموعة الضابطة والمجموعة التجريبية

\begin{tabular}{|c|c|c|c|c|c|c|}
\hline الدلالة & قيمة (ت) & درجات الحرية & الانحراف المعياري & المتوسط & 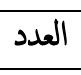 & المهارات التكنولوجية \\
\hline \multirow[t]{2}{*}{$\cdot . \cdot 1$} & $\sum Y, \wedge r$ & $r q$ & $r, \varepsilon \varepsilon$ & $\Gamma, \varepsilon \varepsilon$ & $r \cdot$ & إدراك التفاصيل للأجحزة والبرامج' ضابطة \\
\hline & & & $1, \wedge$. & $r 1,1$. & r. & تجريية \\
\hline \multirow[t]{2}{*}{$\cdot, \cdot 1$} & $r \varepsilon, 1 \wedge$ & rq & $r, \varepsilon \vee$ & $\varepsilon, r$. & $r$. & الملاحظة' ضابطة \\
\hline & & & $T, Y T$ & $19,1 \cdot$ & r. & الملاحظة: تجريبية \\
\hline \multirow[t]{2}{*}{$\cdot, \cdot 1$} & $r 0, \cdot 9$ & rq & $r, r$. & $\varepsilon, 0$. & r. & التصميم التكنولوجي' ضابطة \\
\hline & & & $r, Y \varepsilon$ & $r \cdot, q$. & r. & التصميم التكنولوجي": تجريبية \\
\hline \multirow[t]{2}{*}{$\cdot, \cdot 1$} & 酒 & rq & $r, V \varepsilon$ & 0,7 & $r$. & الحساسية للمشكلات' ضابطة \\
\hline & & & r, ro & $r \cdot, l \cdot$ & r. & الحساسية للمشكلات! تجريبية \\
\hline
\end{tabular}




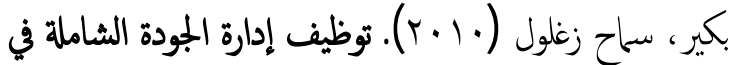

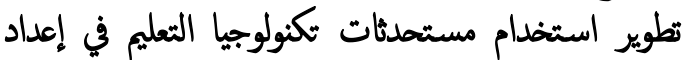
الطلاب المعلمين، (رسالة ماجستير غير منشورة، كلية التربية، جامعة حلوان).

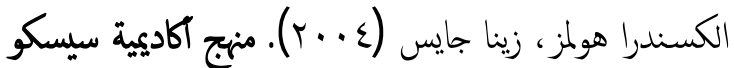

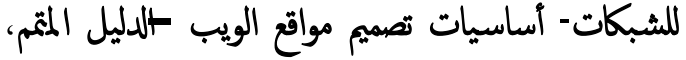
تربهة، مركز النعريب والبرجة، بيروت، الدار العربية للعلوم.

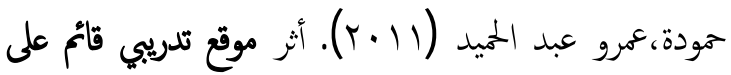

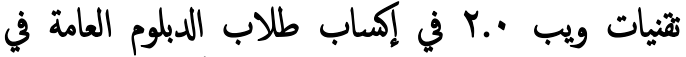

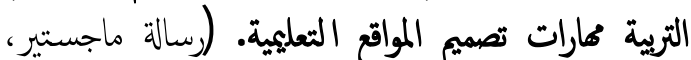
معهد الدراسات التربوية، جامعة القاهرة).

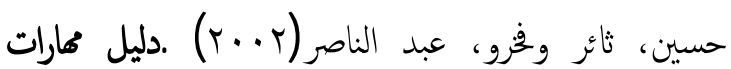
الثفكير عان': جحينة للنشر.

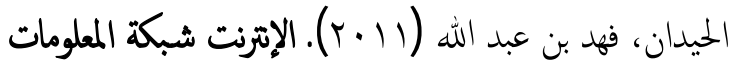
العالمة، الرياض: مكتبة الملك فهد الوطنية.

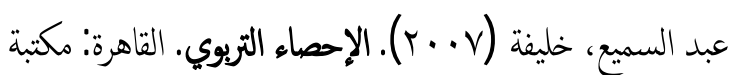
الأنجلو المصرية.

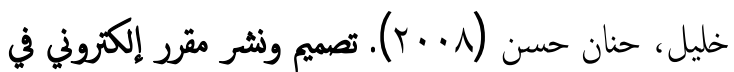
تكنولوجيا التعليم في ضوء معايير جودة التعليم الإلكروني لتنية الجوانب المعرفية والأدائية لدى طلاب كلية كلية التربية. (رسالة ماجستير ،كلية التربية،جامعة المنصورة).

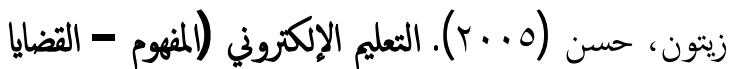
- التخطيط - التطبيق - التتييم). الرياض: الدار الصوتية للتربية.

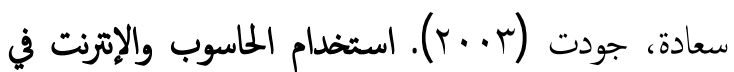
ميادين التريية و التعليم، رام الله: الشروق. المان.

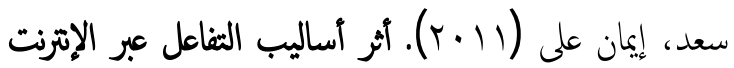

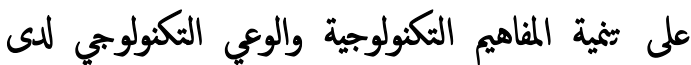

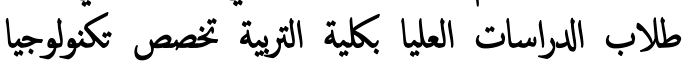
التعليم (رسالة ماجستير ، كلية التربية، جامعة الفيوم).

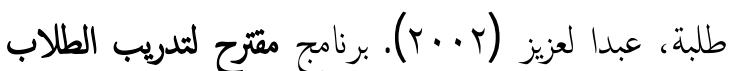

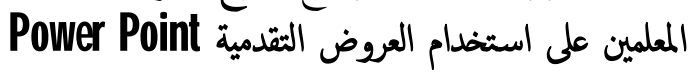
في تصميم وإنتاج بربجيات تعليمية متعددة الوسائط وتينية المئية اتجاهاتهم نحوه، ورقة مقدمة إلى المؤمثر العلمي الرابع عشر
البعدى أعلى من نتائج طالبات المجموعة الضابطة في القياس

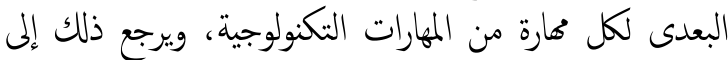

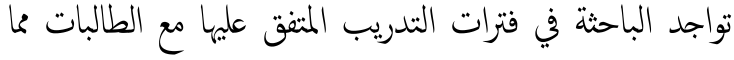

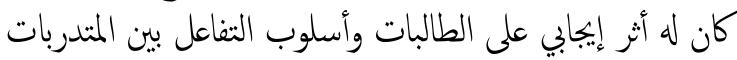

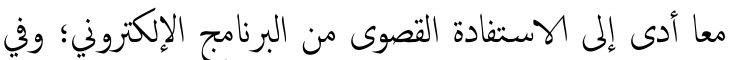

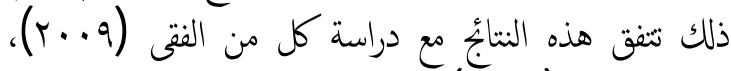

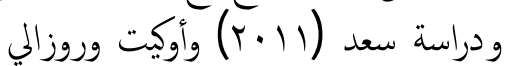
(Ocket. J. \& Rosalie, 2004)

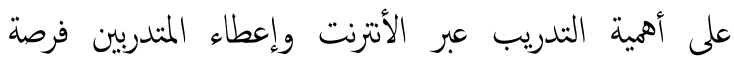

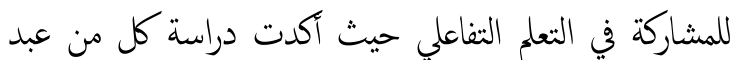

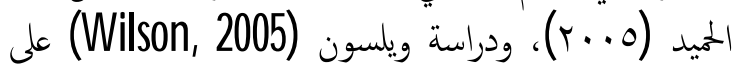

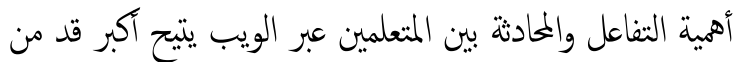

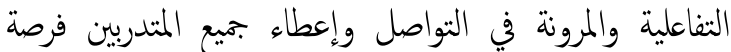

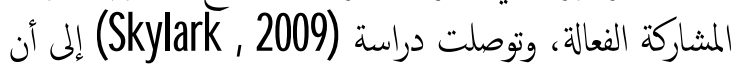

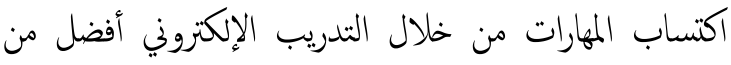
التدريب التقليدي حيث يوفر التواصل والثفاعلية بين المتدربين.

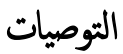

في ضوء النتائج التي أسفر عها البحث الحالي يوصى بما يلي: ا. إعداد مواقع للتعلى الإككتوني على الويب، وفقا' لمعايير وشروط التعلم القائم على الشبكة، تناسب المراحل التعليمية المختلفة.

r. ضرورة عقد دورات تدريية وندوات وورش عمل لئل مستمرة لتدريب أعضاء هيئة الندريس على ما يستجد من تثنيات تعليم. rا. تصميم مواقع إنتزنت مختلفة تقدم برامج تدريية مستمرة

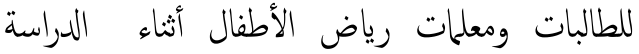
وكذلك أثناء الخدمة في المجالات المختلفة. ع. الاهتمام بتدريب معلمات رياض الأطفال على أنماط التعلم الذاتي والاستفادة منها في تينية قدراتهم المهنية، ومسايرة التطورات، والمستحدثات التكنولوجية التعليمية تلئية التي تؤدى إلى جودة العملية التعليمية. المراجع

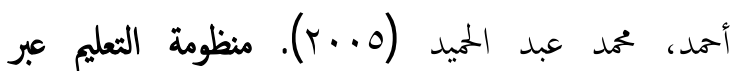

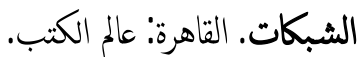




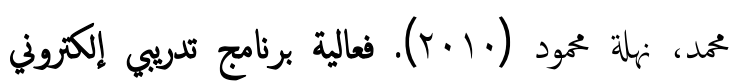

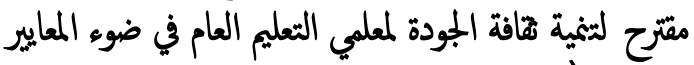

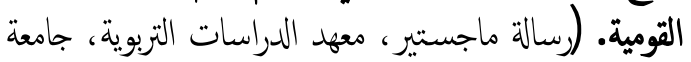

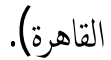

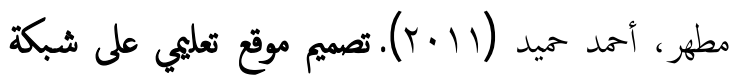

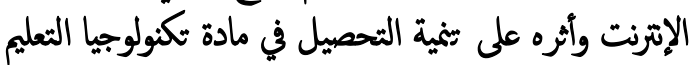
والاتجاهات نحو استخدام الإترنت لدى طلاب الابكية كلية التربية

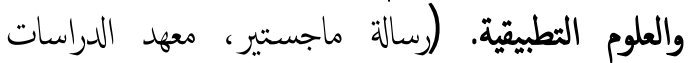

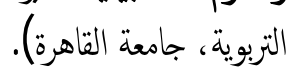

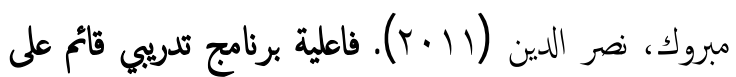

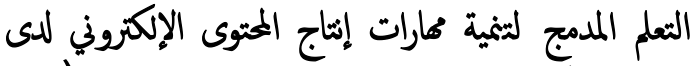

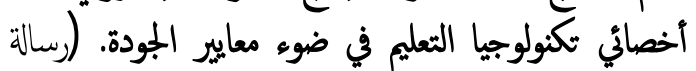
ماجستير ، معهد الدراسات التربوية، جامعة القاهرة).

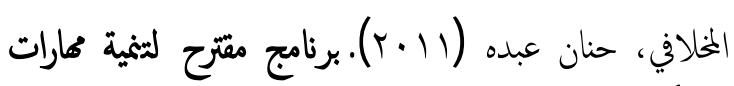

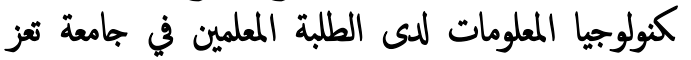

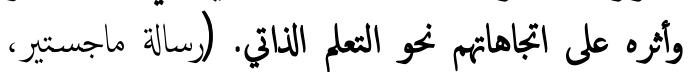
معهد الدراسات التربوية، جامعة القاهرة). سلامة، رضا المواضية (11 • ( ا).التنية المهنية لمربيات رياض

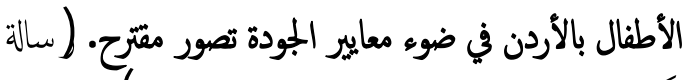
دكتوراه، معهد الدراسات التربوية، جامعة القاهرة).

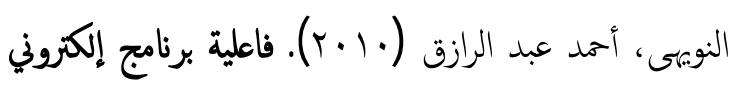

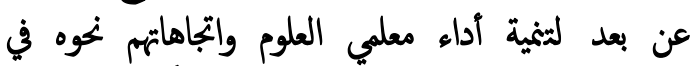

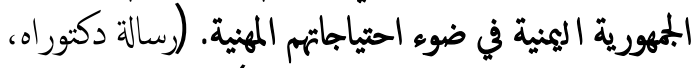
معهد الدراسات التزبوية، جامعة القاهرة).

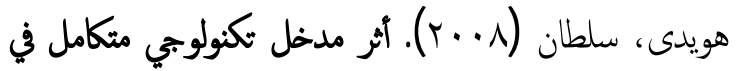

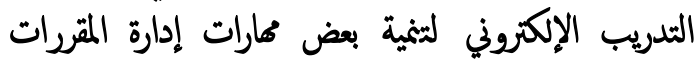
الإلكتونية لدى أعضاء هيئة التدريس بالسعودية واتجاهاتهم

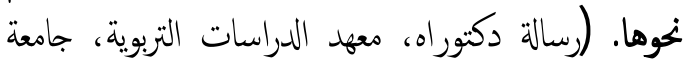

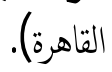

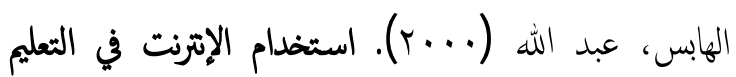

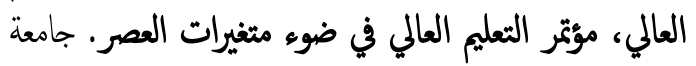

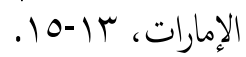

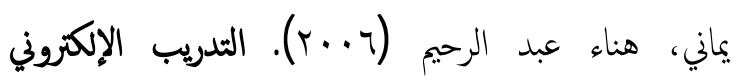

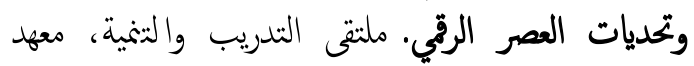

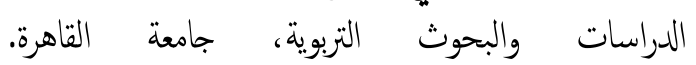

مناجه التعليم في ضوء مفهوم الأداء "، عب-Oب يوليو ، المجلد

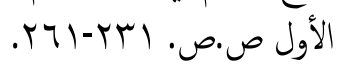

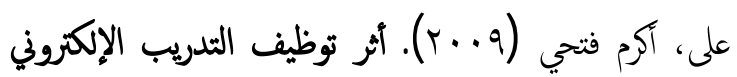

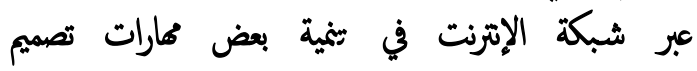
الاختبارات الإلكتونية لدى أعضاء هيئة التدريس بجامعة فئة

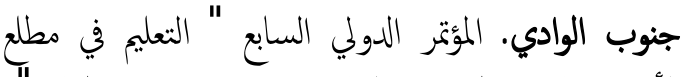

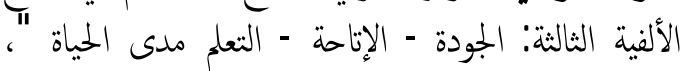

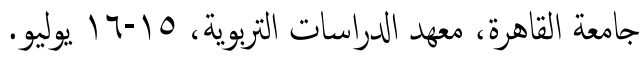

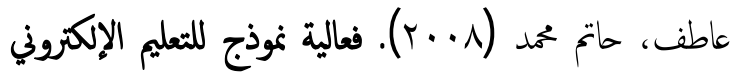
عن بُعد لطلبة الإعلام لإخراج جريدة إلكترونية للأطفال

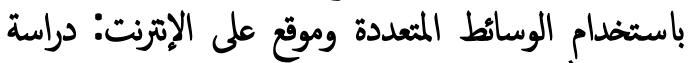

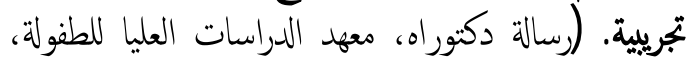
جامعة عين شمس).

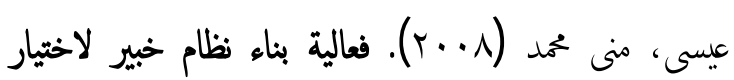

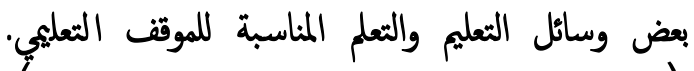
(رسالة ماجستير ، معهد الدراسات التربوية، جامعة القاهرة).

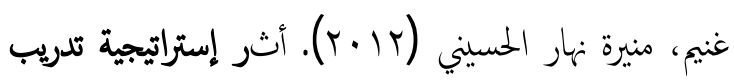

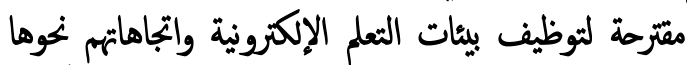

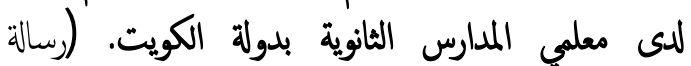
دكتوراه، معهد الدراسات التربوية، جامعة القاهرة).

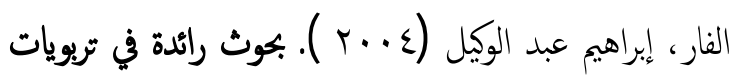

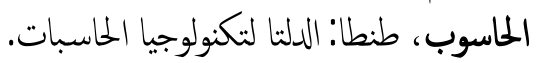

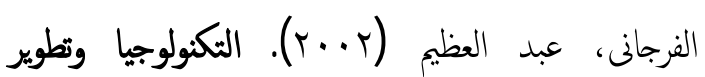

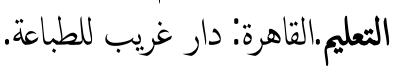

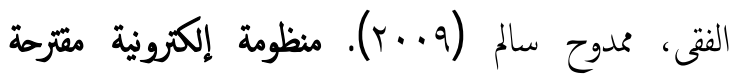

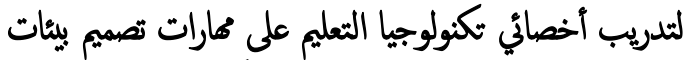

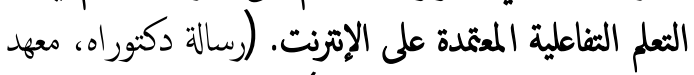
الدراسات التربوية، جامعة القاهرة).

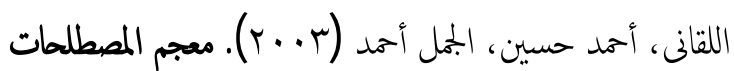
التربوية في المناج وطرق التدريس، القاهرة ':عالم الكنب. المجا.

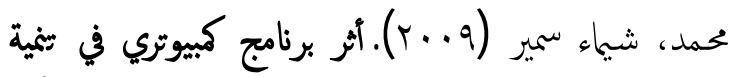
مارات طلاب شعبة معلم الحاسب لتصميم شبكة

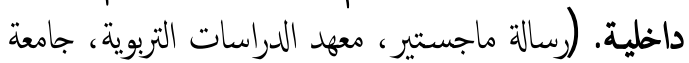

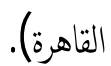


Broadbent, B. (2002). E-learning present and future. Ottawa distance learning group available at: http:/ www.ELearn/ PDF/ papers.

Coffman, T. (2004). Online professional development transferring skills learned to the classroom, CA PELLA University.

Daniel, Y. \& Wang, Y. (2008). Multi-criteria evaluation of the web - based E- learning system. A methodology based-on learner satisfaction and its applications. Computers and Education, 50, 894-905

Fung, C., Kit-Ho, L. \& Chi-Chung (2008). The preprimary education voucher scheme of $\mathrm{H}$ ong Kong: a promise of quality education provision. Chinese University of Hong Kong. ERIC, EJ861872.

Guy, R (2004). An investigation of the effects of instructional strategy (instructor centered) versus learner-centered) and communication mode (synchronous and asynchronous) on student learning and interaction in a web-based environment. D igital D issertations, AAT 3123810.

Hampton, V. R. (2000). The Penn interactive peer play Scale for Kindergarten: Building essential linkages in early childhood assessment. Dissertation A bstracts international section A: Humanities and Social Sciences. Vol .60, PsyclNFO, 200095011-102.

Hong, K., Ridzuan, A. \& Kuent, M. (2003). Students' attitudes toward the use of the internet for learning: A study at a university in Malaysia. Education Technology $\&$ Society, 6(2), 45-49.

Noh. T. and Cha, J. (2004). Perceived professional needs of Korean science teacher majoring in chemical education and their preferences for online and on sit training international. Journal of Science Education 20(10), 1269-1289.

Ocket, R. J. (2004). Collaborative learning environment exploring student attitudes and satisfaction in face to face and asynchronous computer conferencing settings. Journal of Interactive Learning Research, 12, (4).
Pan, YueJuan .Liu, Yan. Lau, Eva Yi Hung (2010). Evaluation of the kindergarten quality rating system in Beijing, ERIC, EJ880244.

Robert A. (2003). Improving students achievement by infusing a web-based curriculum into global history. Journal of Research on Technology in education, 36(1) 7791.

Skylark, A. (2009). A comparison of asynchronous online text-based lectures and synchronous interactive web conferencing lectures, issues in teacher education 18 (2), ERIC. EJ858506.

Stephen J. S. (2003). Active and cooperative Learning using web- based simulations. J ournal of Economic Education, 34 (2), 151.

Stephen, A. \& Stanley, T. (2001). M ultimedia for learning: method and development. USA: Pearson Education Company.

Wilson, D. G., Stacey E. (2005). Online interaction impacts on learning: Teacher to teach online. Australian Journal of Educational Technology, 20, (1), 33-48. 